\title{
Estudos sobre um modelo estocástico para a evolução de uma espécie
}

\author{
Renata Stella Khouri \\ Dissertação apresentada \\ ao Instituto de Matemática e Estatística \\ da Universidade de São Paulo \\ para obtenção do título de \\ Mestre em Ciências \\ Programa: Estatística \\ Orientador: Prof. Dr. Fábio Prates Machado
}

Durante o desenvolvimento deste trabalho a autora recebeu auxílio financeiro do CNPq.

São Paulo, maio de 2013. 



\section{Estudos sobre um modelo estocástico para a evolução de uma espécie}

Esta versão da dissertação contém as correções e alterações sugeridas pela Comissão Julgadora após a defesa realizada em 15 de março de 2013 por Renata Stella Khouri. Uma cópia da versão original está disponível no Instituto de Matemática e Estatística da Universidade de São Paulo.

Comissão Julgadora:

- Prof. Dr. Fábio Prates Machado (orientador) - IME/USP

- Prof. Dr. Élcio Lebensztayn - IMECC/UNICAMP

- Prof. Dr. Fernando Pigeard de Almeida Prado - FFCLRP/USP 


\section{Resumo}

\section{Estudos sobre um modelo estocástico para a evolução de uma espécie}

Apresentamos um modelo estocástico para a evolução de uma espécie pelo processo de seleção natural. Compreender bem o processo evolutivo é de fundamental importância para a biologia, pois é através dele que as espécies e a vida se transformaram ao longo do tempo até chegarmos no mundo como conhecemos hoje. Detalharemos um resultado encontrado na literatura, e também introduzimos algumas variações e sugestões para aprimorar a modelagem original. O modelo proposto é interessante por conta de sua simplicidade e capacidade de capturar aspectos qualitativos esperados segundo as teorias biológicas.

Palavras-chave: modelagem estocástica, evolução, biomatemática

\section{Abstract}

Studies on a stochastic model for the evolution of a species

We present a stochastic model for the evolution of a species by natural selection. A good understanding of the evolutionary process is fundamental for the biological sciences, since it describes how life and all species developed until we reached the world as we know today. We show in details a result available on the literature, and also introduce some variations and suggestions in order to improve the original modeling. The model presented here is interesting due to its simplicity and ability to reproduce some qualitative aspects expected from the biological theories.

Keywords: stochastic modeling, evolution, biomathematics 
"Little particles of inspiration sleet through the universe all the time..." Terry Pratchett 


\section{Agradecimentos}

Ao meu orientador, Fábio Machado, por todos os ensinamentos, dedicação, paciência e liberdade que recebi durante esse projeto.

À minha orientadora durante a graduação, Stefanella Boatto, quem primeiro me mostrou o mundo da pesquisa e muito da diversão que ele pode oferecer.

A todos os amigos e colegas que doaram seu tempo para ouvir sobre esse trabalho, em particular: Lucas Stolerman (meu irmão acadêmico, sempre aí pra trocar uma idéia), Fábio Lopes (que me fez enxergar um caminho bem mais simples para o resultado da seção 4.2) e Alex Schomaker (pelas várias dicas de leitura e revisão da parte biológica do texto).

Por último, mas não menos importante, à minha família que continua me apoiando nessa idéia de fazer ciência. Principalmente minha irmã, Rebeca, que me cedeu as fotos para a seção 2.2 e também seu videogame durante os feriados que passei no Rio. 


\section{Sumário}

1 Introdução $\quad 1$

1.1 Motivação . . . . . . . . . . . . . . . . . . . . . . . . . 1

1.2 Organização do texto . . . . . . . . . . . . . . . . 1

2 Fundamentos 3

2.1 Matemática . . . . . . . . . . . . . . . . . . . 3

2.1 .1 Passeio aleatório . . . . . . . . . . . . . . . . . . . 3

2.1 .2 Ruína do jogador . . . . . . . . . . . . . . . . . . . . . 6

2.1 .3 Filas com prioridade . . . . . . . . . . . . . . . . . . 7

2.1 .4 Cadeias de Markov . . . . . . . . . . . . . . . . . . . . 9

2.2 Biologia . . . . . . . . . . . . . . . . . . . . . . . . . . . 10

2.2 .1 O que é evolução? . . . . . . . . . . . . . . . . . . . . . . . . . . . . . . . . . . . . . .

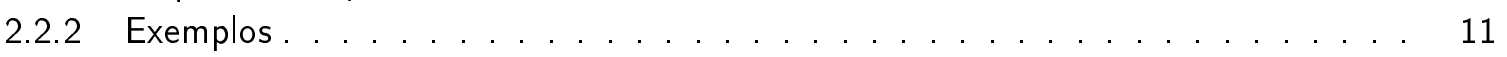

2.2 .3 Mini-glossário . . . . . . . . . . . . . . . . . . . . . . . . 12

30 modelo GMS 15

3.1 Modelo a tempo contínuo . . . . . . . . . . . . . . . . . . . . . . . . . . . . .

3.2 Modelo a tempo discreto . . . . . . . . . . . . . . . . . 22

4 Variações do modelo 23

4.1 Caso subcrítico . . . . . . . . . . . . . . . . . . . . . . . . . 23

4.2 Ambiente com capacidade finita . . . . . . . . . . . . . . . . 26

5 Comentários, críticas, conclusões 29

5.1 Comparação . . . . . . . . . . . . . . . . . . . . . . . . . 29

5.1 .1 Modelo Bak-Sneppen ... . . . . . . . . . . . . . . . . . . . . . . 29

5.1 .2 Modelo GMS . . . . . . . . . . . . . . . . . . . . . 30

5.2 Discussão . . . . . . . . . . . . . . . . . . . . . . . . . . 30

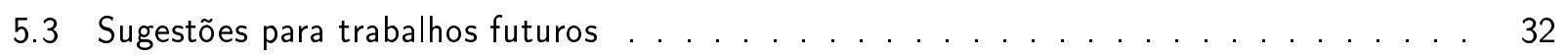

$\begin{array}{ll}\text { Referências Bibliográficas } & 35\end{array}$ 


\section{Capítulo 1}

\section{Introdução}

\subsection{Motivação}

Existem muitas teorias e discussões biológicas para explicar a evolução, processo através do qual os seres vivos se desenvolvem e se transformam constantemente.

Um dos fatores que influencia a evolução é a chamada seleção natural. Descrita inicialmente por Darwin em $A$ Origem das Espécies [4], ocorre quando indivíduos de uma espécie são submetidos a algum tipo de pressão externa, e aqueles mais bem adaptados às condições ambientais passam a ter maiores chances de sobreviver que os demais.

Através da compreensão desses processos podemos aprender mais sobre como e porque o mundo e a natureza se modificaram ao longo do tempo, daí o interesse em estudá-los.

Nessa dissertação exploraremos um modelo para a evolução (que chamaremos GMS, veja [12] [13]). Motivado como uma alternativa ao modelo de Bak-Sneppen [2] para o processo de evolução entre espécies, o modelo GMS é interessante por sua simplicidade e capacidade de descrever alguns aspectos qualitativos do problema biológico. Também apresentaremos algumas sugestões de possíveis variações para este modelo.

Apesar de matematicamente diferentes, os dois modelos apresentam algumas imprecisões com relação aos conceitos biológicos envolvidos. Discutiremos mais esse assunto no capítulo final desta dissertação.

\subsection{Organização do texto}

O capítulo 2 tem como objetivo apresentar as ferramentas que serão necessárias para o estudo do modelo. Pode-se começar a leitura diretamente pelo capítulo 3, retornando se necessário conforme seja referenciado ao longo do texto.

No capítulo 2 encontramos alguns resultados básicos de passeios aleatórios e teoria de filas, que usaremos na demonstração de proposições e teoremas dos capítulos seguintes. Esta parte foi escrita pensando também na (remota porém não nula) possibilidade de um biólogo desavisado decidir ler esse texto, portanto a linguagem pretende ser mais simples.

Ainda nesse capítulo temos uma breve introdução informal a conceitos de ecologia e genética de populações, importantes para uma melhor compreensão do problema que queremos modelar. Esta parte foi escrita pensando em um leitor não muito familiarizado com a terminologia e as idéias biológicas envolvidas. Assim, espero que o eventual biólogo do parágrafo anterior me perdoe por qualquer imprecisão. 
No capítulo 3 apresentamos o modelo GMS (encontrado nos artigos [12] [13] [14]) e algumas de suas principais características e resultados.

O capítulo 4 contém dois resultados para variações do modelo. Um é referente ao tempo médio de sobrevivência no sistema para o caso em que a taxa de mortalidade é mais alta que a taxa de surgimento de novos tipos de indivíduo no ambiente. O outro trata de uma variação do modelo onde é possível mostrar que o comportamento teórico condiz com um aspecto esperado em uma população na natureza.

Por fim, no capítulo 5 apresentamos uma descrição mais detalhada do modelo de Bak-Sneppen e uma comparação com o modelo GMS. Além disso, fazemos algumas críticas relativas aos aspectos biológicos dos modelos acima citados, assim como sugestões para projetos futuros.

Observação: todas as simulações ao longo do texto foram feitas usando o ( $($ tttp://www.R-project.org/). 


\section{Capítulo 2}

\section{Fundamentos}

Como mencionado anteriormente, este é um capítulo de referência, e pode ser omitido caso o leitor já esteja familiarizado com a teoria.

\subsection{Matemática}

Nesta seção seguiremos as idéias e notações de Feller [7], Ross [23] [24], Schinazi [26] e Virtamo [30].

$$
\begin{aligned}
\text { Observações: } & \mathbb{N}=\{0,1,2,3, \ldots\} \\
& \mathbb{P}(A)=\text { probabilidade do evento } A \text { acontecer. } \\
& \mathbb{E}(X)=\text { esperança (valor médio) da variável aleatória } X . \\
& \text { a notação } x_{n} \approx y_{n} \text { significa } \lim _{n \rightarrow \infty} \frac{x_{n}}{y_{n}} \rightarrow 1 .
\end{aligned}
$$

\subsubsection{Passeio aleatório}

Imagine um sapo parado no degrau de uma escada. A cada minuto ele pula para cima ou para baixo. Mas ele sofre com perda de memória recente, e portanto a escolha do salto acontece independentemente do trajeto anterior.

Vamos numerar os degraus de maneira que a posição inicial do sapo é 0 .

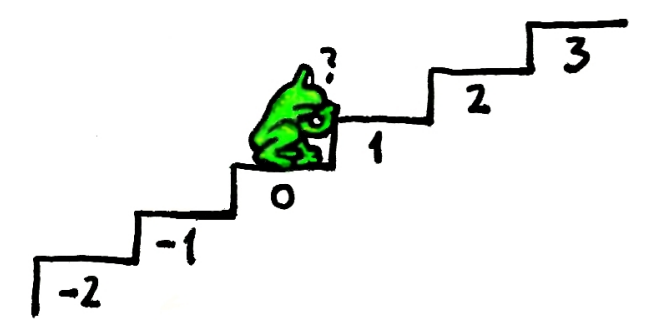

Fixe um instante de tempo $m$. Sejam $c$ o número de saltos para cima e $b$ o número de saltos para baixo até esse instante (ou seja, $b+c=m$ ). Note que, se representarmos os saltos num gráfico, teríamos um caminho começando em $(0,0)$ e terminando em $(m, x)$, onde $x=c-b$. 


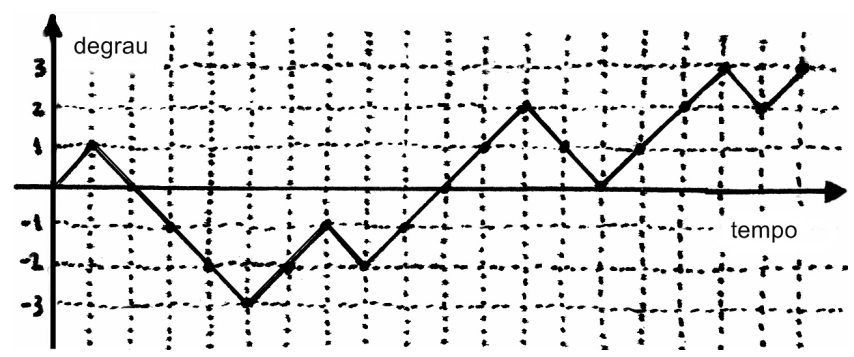

Figura 2.1: Um exemplo de possíveis saltos realizados pelo sapo.

Aqui vale observar que qualquer caminho da origem a $(m, x)$ terá $c$ saltos para cima e $b$ saltos para baixo. A volta também vale: qualquer caminho partindo da origem $\operatorname{com} c$ saltos para cima e $b$ saltos para baixo terminará em $(m, x)$.

Assim, teremos $N_{m, x}$ possíveis caminhos da origem até $(m, x)$, onde:

$$
N_{m, x}=\left(\begin{array}{c}
b+c \\
b
\end{array}\right)=\left(\begin{array}{c}
b+c \\
c
\end{array}\right)
$$

Podemos representar o caminho percorrido por nosso sapo amnésico como uma sequência $\left\{X_{j}, j \in \mathbb{N}\right\}$, onde cada $X_{j} \in\{-1,+1\}$. Assim, a posição no $m$-ésimo minuto será $S_{m}=\sum_{j=1}^{m} X_{j}$. Mas temos que $\left\{S_{m}, m \in \mathbb{N}\right\}$ descreverá exatamente o caminho percorrido pelo sapo. A esse processo daremos o nome de passeio aleatório.

Observemos que a probabilidade do sapo estar no degrau $j$ após $m$ saltos vale

$$
\mathbb{P}\left(S_{m}=j\right)=\frac{N_{m, j}}{2^{m}}=\left(\begin{array}{c}
m \\
(m+j) / 2
\end{array}\right) \frac{1}{2^{m}}
$$

Um retorno à origem ocorre no tempo $m=2 n$ se $S_{2 n}=0$. Precisaremos da probabilidade desse evento mais a frente. Vamos chamá-la de $u_{2 n}$ :

$$
u_{2 n}=\mathbb{P}\left(S_{2 n}=0\right)=\left(\begin{array}{c}
2 n \\
n
\end{array}\right) \frac{1}{2^{2 n}}
$$

Lembrando a aproximação de Stirling:

$$
k ! \approx(2 \pi)^{1 / 2} e^{-k} k^{k+\frac{1}{2}}
$$

Podemos escrever:

$$
\begin{aligned}
u_{2 n} & =\left(\begin{array}{c}
2 n \\
n
\end{array}\right) \frac{1}{2^{2 n}}=\frac{(2 n) !}{n ! n !} \frac{1}{2^{2 n}} \\
& \approx \frac{1}{\sqrt{(2 \pi)}} \frac{(2 n)^{2 n+\frac{1}{2}}}{n^{2 n+1}} \frac{1}{2^{2 n}} \\
& \approx \frac{1}{\sqrt{(n \pi)}}
\end{aligned}
$$

Temos enfim o seguinte 
Lema 2.1. (vide cap. III.3 de Feller [7])

A probabilidade de nenhum retorno à origem acontecer até o tempo $2 n$ é igual a probabilidade de ocorrer um retorno no tempo $2 n$. Isto é,

$$
\mathbb{P}\left(S_{1} \neq 0, \cdots S_{2 n} \neq 0\right)=\mathbb{P}\left(S_{2 n}=0\right)=u_{2 n}
$$

\section{Demonstração.}

Aqui usaremos um argumento gráfico sugerido por Feller [7] para mostrar que o número de caminhos com $2 n$ passos que nunca tocam o zero é igual ao números de caminhos ligando a origem ao ponto $(2 n, 0)$.

Considere um caminho que chega ao zero no $2 n$-ésimo passo. (A) Procure o primeiro ponto a partir da esquerda com menor coordenada no eixo vertical, depois (B) "recorte" a parte que vai da origem até este ponto. Reflita esse trecho em relação ao eixo vertical. (C) "Cole" o pedaço refletido no final do caminho original, e (D) reposicione os eixos de modo que a origem esteja posicionada no antigo ponto de mínimo.

Obtemos assim um caminho com $2 n$ passos que nunca retorna ao eixo horizontal. Graficamente:
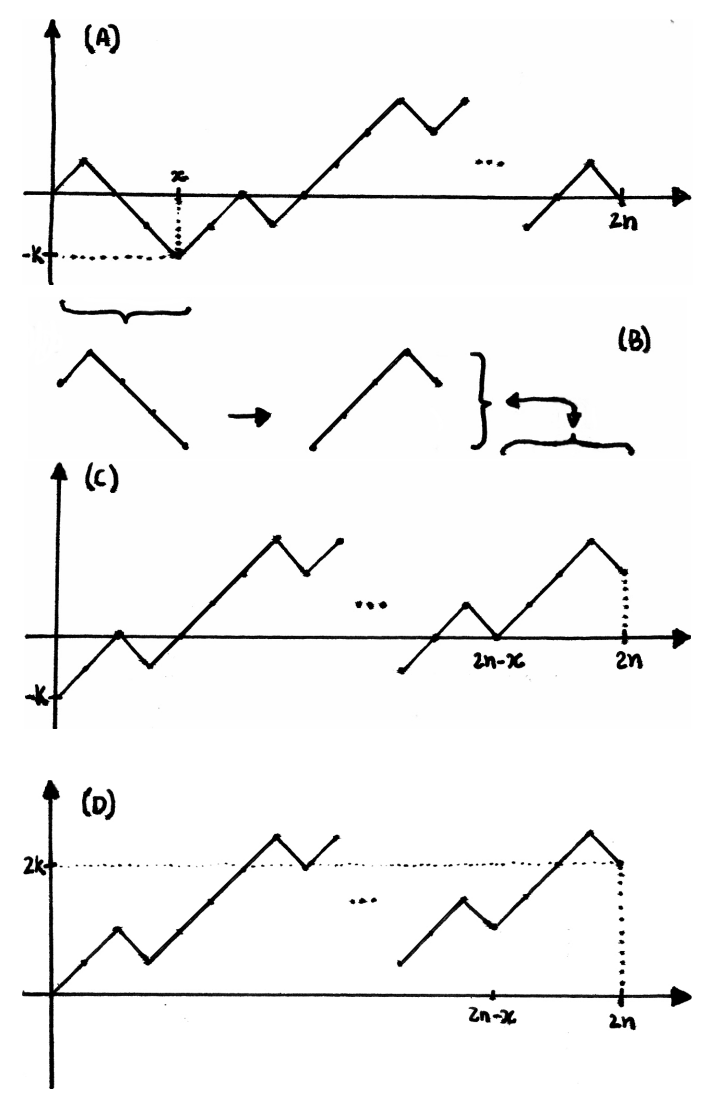

Figura 2.2: Ilustração do lema 2.1.

Podemos usar o mesmo argumento para a volta: considere um caminho de $2 n$ passos que nunca toca 0 eixo horizontal, e seja $(2 n, 2 k)$ o ponto em que ele termina.

Desloque o eixo horizontal de $k$ unidades para cima, e procure o primeiro ponto a partir da direita onde o caminho toca o zero. "Recorte" essa parte do caminho e reflita-a com relação ao eixo vertical. Depois, "cole" o pedaço refletido na origem e reposicione os eixos de modo que a origem esteja no primeiro ponto do caminho. 
Obtemos assim um caminho que chega ao zero no tempo $2 n$.

Ou seja, existe uma bijeção entre o conjunto dos caminhos que retornam à origem no tempo $2 n$ e o conjunto dos caminhos que nunca retornam à origem até o tempo $2 n$. Portanto, a probabilidade de um caminho qualquer pertencer ao primeiro ou segundo conjunto é a mesma.

\subsubsection{Ruína do jogador}

Imagine um jogo de azar onde a cada rodada um apostador pode ganhar ou perder $R \$ 1 \mathrm{com}$ probabilidade $p$ ou $q=1-p$, respectivamente. As rodadas são independentes entre si. Vamos supor também que o apostador só vai sair do jogo se perder todo o seu dinheiro.

A fortuna desse jogador é um passeio aleatório assumindo valores em $\mathbb{N}$. Se o passeio em algum momento atinge o zero, ele não sairá mais de lá. Isto é, $\mathbb{P}\left(X_{n+1}=0 \mid X_{n}=0\right)=1$ para todo $n \in \mathbb{N}$.

Qual é a probabilidade da fortuna do apostador atingir o valor $R \mathbb{} N$ nesse jogo?

Seja $f_{j}$ a probabilidade do jogador ganhar $R \mathbb{} N$ começando com um montante inicial de $R \mathbb{} j$, onde $j \in\{1,2, \cdots, N-1\}$. Condicionando no resultado da primeira rodada,

$$
\begin{gathered}
f_{j}=p f_{j+1}+q f_{j-1} \\
\Downarrow \\
f_{j+1}-f_{j}=\frac{1-p}{p}\left(f_{j}-f_{j-1}\right)
\end{gathered}
$$

Como $f_{0}=0$, podemos escrever:

$$
\begin{aligned}
& f_{2}-f_{1}=\frac{q}{p}\left(f_{1}-f_{0}\right)=\frac{q}{p} f_{1} \\
& f_{3}-f_{2}=\frac{q}{p}\left(f_{2}-f_{1}\right)=\left(\frac{q}{p}\right)^{2} f_{1} \\
& \vdots \\
& f_{N}-f_{N-1}=\frac{q}{p}\left(f_{N-1}-f_{N-2}\right)=\left(\frac{q}{p}\right)^{N-1} f_{1}
\end{aligned}
$$

Ou seja,

$$
f_{j}= \begin{cases}\frac{1-(q / p)^{j}}{1-(q / p)} f_{1} & \text { se } p \neq 1 / 2 \\ j f_{1} & \text { se } p=1 / 2\end{cases}
$$

Usando o fato de que $f_{N}=1$, encontramos

$$
f_{1}= \begin{cases}\frac{1-(q / p)}{1-(q / p)^{N}} & \text { se } p \neq 1 / 2 \\ \frac{1}{N} & \text { se } p=1 / 2\end{cases}
$$


E daí,

$$
f_{j}= \begin{cases}\frac{1-(q / p)^{j}}{1-(q / p)^{N}} & \text { se } p \neq 1 / 2 \\ \frac{j}{N} & \text { se } p=1 / 2\end{cases}
$$

Agora, observemos que

$$
\lim _{N \rightarrow \infty} f_{j}= \begin{cases}1-(q / p)^{j} & \text { se } p>1 / 2 \\ 0 & \text { se } p \leq 1 / 2\end{cases}
$$

Ou seja, se $p>1 / 2$ existe uma probabilidade positiva da fortuna do jogador crescer indefinidamente. Mas se $p \leq 1 / 2$, com probabilidade 1 o jogador eventualmente perderá todo o seu dinheiro.

\subsubsection{Filas com prioridade}

Imagine que uma agência bancária está com apenas um caixa eletrônico disponível para a realização de saques. Esse caixa possui dinheiro suficiente para atender qualquer número de clientes.

Pessoas chegam para fazer saques de acordo com um processo de Poisson de taxa $\lambda$ e permanecem no caixa até terminarem a operação. Vamos supor que a distribuição do tempo de atendimento é exponencial com parâmetro $\mu$.

Se o caixa estiver ocupado no momento em que um cliente chega, este espera numa fila até que todos os clientes na sua frente tenham retirado seu dinheiro.

Os tempos de atendimento são independentes entre si (pois o caixa tem dinheiro suficiente para todos os clientes) e identicamente distribuídos (todos os clientes realizam apenas saques) segundo uma distribuição $A$.

Quanto tempo em média um cliente vai esperar na fila até sua vez de usar o caixa?

Se $\tau$ é a variável que mede o tempo de espera na fila,

$$
\mathbb{E}(\tau)=\frac{1}{\mu} \mathbb{E}(L)+\mathbb{E}(R)
$$

onde $1 / \mu$ é o tempo médio que um cliente passa na fila; $L$ é a variável que representa o número de clientes esperando na fila; e $R$ é a variável que representa o tempo residual de atendimento do cliente no caixa.

Para encontrar $\mathbb{E}(L)$ vamos usar o seguinte

Teorema 2.1 (Little). (vide cap. 8 de Ross [24] ou Virtamo [30])

Sejam $\lambda$ a taxa média de chegada de clientes no sistema; $\tau$ o tempo que um cliente gasta no sistema; e $L$ o número de clientes no sistema. Então $\mathbb{E}(L)=\lambda \mathbb{E}(\tau)$. 
Aplicando o teorema, podemos escrever

$$
\begin{gathered}
\mathbb{E}(\tau)=\frac{\lambda}{\mu} \mathbb{E}(\tau)+\mathbb{E}(R) \\
\Downarrow \\
\mathbb{E}(\tau)=\frac{\mathbb{E}(R)}{(1-\lambda / \mu)}
\end{gathered}
$$

Para encontrar $\mathbb{E}(R)$, observemos que o gráfico de $R$ em função de $t$ terá a seguinte forma:

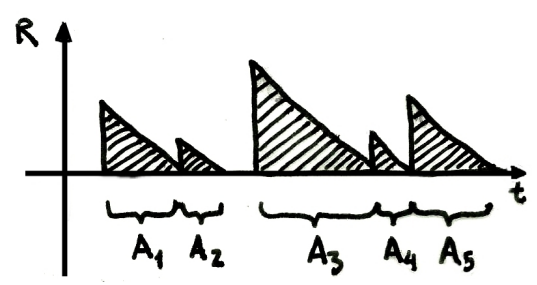

onde $A_{j}=$ variável do tempo de atendimento do cliente $j$.

Assim, o valor médio do tempo residual de atendimento será:

$$
\begin{aligned}
\mathbb{E}(R) & =\lim _{t \rightarrow \infty} \frac{1}{t} \int_{0}^{t} R(s) d s \\
& =\lim _{t \rightarrow \infty} \frac{1}{t} \sum_{j=1}^{n(t)} \frac{1}{2} A_{j}^{2}
\end{aligned}
$$

onde $n(t)$ é o número de atendimentos até $o$ tempo $t$.

Observe que esse número depende da taxa de chegada de clientes, e em média temos $n(t)=\lambda t$.

Portanto, podemos escrever:

$$
\begin{aligned}
\mathbb{E}(R) & =\frac{1}{2} \lim _{t \rightarrow \infty} \frac{n(t)}{t} \frac{1}{n(t)} \sum_{j=1}^{n(t)} A_{j}^{2} \\
& =\frac{\lambda}{2} \mathbb{E}\left(A^{2}\right)
\end{aligned}
$$

Lembrando aqui que $A$ é a variável que segue a distribuição dos tempos de atendimento.

Substituindo (2.7) em (2.6), temos enfim

$$
\mathbb{E}(\tau)=\frac{\lambda}{\mu(1-\lambda / \mu)}=\frac{\lambda}{\mu(\mu-\lambda)}
$$

Suponhamos agora que existem $n$ tipos diferentes de cliente. Clientes tipo 1 têm prioridade sobre clientes tipo 2 , que têm prioridade sobre clientes tipo 3 e assim por diante.

Isso significa que um cliente tipo $b$ nunca será atendido antes de um cliente tipo a que esteja esperando na fila (com $1 \leq a<b \leq n$ ). Porém, se um cliente tipo $b$ já está sendo atendido quando chega um 
cliente tipo $a$, este espera a sua vez até o final do atendimento do outro cliente.

Formalmente, temos $n$ processos de Poisson para as chegadas dos diferentes tipos de clientes. Ou seja, clientes do tipo $j$ chegam na fila a uma taxa $\lambda_{j}, j \in\{1,2, \cdots, n\}$. Os tempos dos atendimentos são iguais para todos os tipos de cliente, e seguem uma distribuição exponencial de parâmetro $\mu$.

Quais os tempos de espera na fila para cada tipo de cliente?

Podemos proceder de forma semelhante ao que fizemos para uma fila sem prioridades (vide, por exemplo, Ross [24] e Virtamo [30]) para concluir que

$$
\begin{aligned}
& \mathbb{E}\left(\tau_{1}\right)=\frac{\lambda_{1}+\cdots+\lambda_{n}}{\mu\left(\mu-\lambda_{1}\right)} \\
& \quad \vdots \\
& \mathbb{E}\left(\tau_{j}\right)=\frac{\lambda_{1}+\cdots+\lambda_{n}}{\mu^{2}\left(1-\frac{1}{\mu}\left(\lambda_{1}+\cdots+\lambda_{j-1}\right)\right)\left(1-\frac{1}{\mu}\left(\lambda_{1}+\cdots+\lambda_{j}\right)\right)} \\
& \quad \vdots \quad \lambda_{1}+\cdots+\lambda_{n} \\
& \mathbb{E}\left(\tau_{n}\right)=\frac{\mu^{2}\left(1-\frac{1}{\mu}\left(\lambda_{1}+\cdots+\lambda_{n-1}\right)\right)\left(1-\frac{1}{\mu}\left(\lambda_{1}+\cdots+\lambda_{n}\right)\right)}{}
\end{aligned}
$$

\subsubsection{Cadeias de Markov}

Uma cadeia de Markov é um tipo de processo estocástico com a seguinte caracerística: sabendo apenas o estado do processo no presente podemos fazer previsões sobre o futuro, sem necessidade de conhecer o histórico passado da cadeia.

Por exemplo, passeios aleatórios são um tipo especial de cadeia de Markov: para decidir qual será o próximo passo precisamos apenas conhecer a posição do passeio no presente.

Formalmente, seja $\left\{\left(X_{n}\right), n \in \mathbb{N}\right\}$ uma sequência de variáveis aleatórias definidas num mesmo espaço de probabilidades e assumindo valores num conjunto enumerável $A$. Dizemos que $X_{n}$ é uma cadeia de Markov se

$$
\mathbb{P}\left(X_{n+1}=j \mid X_{1}=i_{1}, X_{2}=i_{2}, \ldots, X_{n-1}=i_{n-1}, X_{n}=i\right)=\mathbb{P}\left(X_{n+1}=j \mid X_{n}=i\right)
$$

Para simplificar a notação, sejam:

$$
\left\{p(i, j)=\mathbb{P}\left(X_{n+1}=j \mid X_{n}=i\right)\right\} \text { para } i \text { e } j \in A
$$

as probabilidades de transição do processo.

Seguindo uma definição de Schinazi [26], chamemos de cadeia de nascimento-morte qualquer processo de Markov definido nos inteiros positivos com probabilidades de transição:

$$
p_{j}=p(j, j+1) \quad q_{j}=p(j, j-1) \quad r_{j}=p(j, j)
$$


e $p_{j}+q_{j}+r_{j}=1$ para cada $j \in \mathbb{N}$, com $q_{0}=0$.

Dizemos que o estado $j$ é recorrente se a probabilidade da cadeia retornar a $j$ em tempo finito é 1 . A cadeia será recorrente positiva se além disso o tempo médio para que aconteça o retorno for finito.

Vamos usas as seguintes proposições no capítulo 3. A demonstração desses resultados pode ser encontrada, por exemplo, em Schinazi [26].

\section{Proposição 2.1.}

Uma cadeia de nascimento-morte conforme definida acima será recorrente se, e somente se,

$$
\sum_{j=1}^{\infty} \frac{q_{1} q_{2} \cdots q_{j}}{p_{1} p_{2} \cdots p_{j}}=\infty
$$

Proposição 2.2.

Uma cadeia de nascimento-morte será recorrente positiva se vale a proposição 2.1 e

$$
\sum_{j=1}^{\infty} \frac{p_{0} p_{1} \cdots p_{j-1}}{q_{1} q_{2} \cdots q_{j}}<\infty
$$

\subsection{Biologia}

As informações dessa seção foram retiradas principalmente dos livros de Fisher [8], Gould [10], Mayr [18] e Ridley [22].

As ciências biológicas têm se mostrado uma imensa fonte de inspiração para a modelagem matemática. Além de motivarem o estudo e desenvolvimento de ferramentas teóricas, também permitem que fenômenos naturais sejam melhor compreendidos graças à modelagem.

Apresentaremos aqui um resumo informal de conceitos básicos em ecologia e teoria da evolução.

\subsubsection{O que é evolução?}

Essa é a primeira pergunta a se fazer uma vez que decidimos modelar esse processo. Ao invés de tentar definir com todos os detalhes os conceitos biológicos envolvidos, ficaremos com uma idéia mais intuitiva: evolução é o processo através do qual os seres vivos se modificam ao longo do tempo.

Mais importante para uma boa modelagem é entender também os fatores que geram a evolução. Alguns desses principais fatores são migração, mutação, deriva gênica e seleção natural. Todos estão sempre atuando (em maior ou menor escala) em qualquer população na natureza.

Pdemos pensar a migração da seguinte forma. Se uma população recebe influência externa de outras populações diferentes, podem aparecer alterações no comportamento dos indivíduos que a compõem e também nas frequências gênicas da população original (por conta de cruzamentos com indivíduos que migraram para este local, etc.).

Uma mutação que apareça na população também pode gerar evoluạo na medida em que está introduzindo uma nova variedade genética na população original. 
A deriva gênica representa os efeitos do acaso na população. Mesmo indivíduos com uma genética altamente favorável a sobrevivência podem morrer por conta de algum "azar" (como, por exemplo, um desastre natural).

Por fim, a seleção natural. A viariabilidade genética entre diferentes indivíduos numa população produz genótipos particularmente bem adaptados ao ambiente, que passam a ter maiores chances de sobreviver que os demais. Ou seja, os indivíduos com genes melhor adaptados às condições ambientais passam a ter algum tipo de vantagem sobre os demais na luta pela sobrevivência. Esse conceito foi descrito primeiramente por Charles Darwin em "A Origem das Espécies"(1859).

Durante esse texto, focaremos nossa modelagem no processo de evolução por seleção natural.

\subsubsection{Exemplos}

Ilustraremos algumas dessas idéias através de exemplos.

\section{Exemplo 2.1.}

Escolha um parque no qual te agrada passear, e caminhe pelos jardins. Você provavelmente observará borboletas nas mais diversas cores: azuis, amarelas, vermelhas, quase transparentes. Elas também são de diferentes tamanhos, e possivelmente estão em lugares distintos do parque.

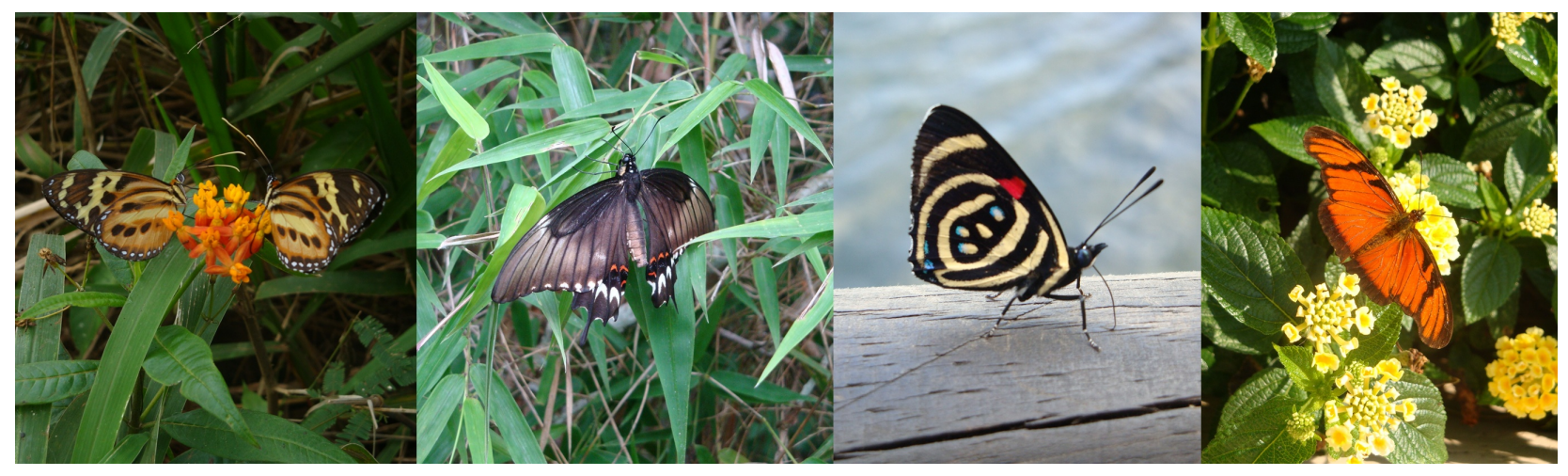

Figura 2.3: Fotos por Rebeca Stella Khouri

Não é muito difícil imaginar que "tipos" diferentes pertencem a espécies diferentes. Mas podemos nos perguntar: por que cada espécie é do jeito que é? Seria mais ou menos vantajoso possuir asas grandes e azuis do que pequenas e alaranjadas?

Olhe para aquela borboleta pequena de asas escuras. Estamos vendo várias outras como ela, mas também uma ou duas quase idênticas, exceto pelas asas, que são amarelas. Será que existe algum motivo para essa discrepância? Se elas são da mesma espécie, por que apresentam essa variação de cores?

As respostas podem nos ajudar a entender melhor como funciona o processo da evolução.

Cada uma dessas características da borboleta está codificada em diferentes genes do seu DNA. O conjunto dos genes de um indivíduo se chama genótipo. Em conjunto com fatores ambientais, o genótipo é responsável por gerar todas as características que observamos na borboleta, inclusive a cor de suas asas.

Encontramos evidências de que há muitos anos essa espécie de borboletas vivia livremente nessa região, e que era possível observar não apenas borboletas escuras ou amarelas, mas também com várias outras 
cores para suas asas. Por que então hoje a maioria das borboletas dessa espécie têm asas escuras?

Também encontramos evidências de que, num determinado momento, veio para essa região uma espécie de passarinho que se alimentava dessa borboleta. Por conta das asas coloridas e chamativas, os passarinhos conseguiam encontrar facilmente suas presas. Mas aquelas borboletas que possuíam genética determinando cor escura para as asas eram mais dificilmente capturadas, porque conseguiam se "disfarçar" nos troncos de árvores e plantas. Portanto, possuir asas escuras tornou-se uma vantagem para a sobrevivência: borboletas assim seriam mais dificilmente predadas pelos passarinhos.

Dessa forma, com o passar das gerações, o genótipo para asas escuras tornou-se predominante. Isso ocorreu porque borboletas com asas escuras tinham maior probabilidade de sobreviver e se reproduzir, transmitindo suas características genéticas à sua prole.

Essa população de borboletas, na qual inicialmente as mudanças de coloração aconteciam somente por conta do acaso, foi submetida a uma pressão ambiental (o surgimento de um predador) e passou por um processo de seleção natural. O gene que determina asas escuras, mais bem adaptado ao ambiente, foi selecionado sobre os demais para asas coloridas.

\section{Exemplo 2.2.}

Imagine uma placa de Petri para cultura de bactérias, onde inicialmente colocamos uma única bactéria e a deixamos crescer e se reproduzir até formar uma colônia completa.

Não exercemos nenhuma influência externa sobre o crescimento da população, apenas providenciamos o necessário para que as bactérias cresçam e se reproduzam livremente.

A bactéria inicial era vulnerável a determinado tipo de antibiótico. Mas, uma vez que mutações podem ocorrer com alguma facilidade nestes microorganismos, vamos supor que após algum tempo surgiram na população algumas bactérias com genes determinando a resistência ao antibiótico.

Após o crescimento da colônia vamos aplicar um pouco de antibiótico na placa. O que acontece?

Os indivíduos melhor adaptados ao novo ambiente são aqueles com genótipo determinando resistência ao antibiótico. Eles têm mais chance de sobreviver e de produzir descendentes na população do que aqueles que não apresentam resistência. Estes últimos provavelmente terão desparecido após algumas aplicações do antibiótico.

Essa população de bactérias, na qual inicialmente a presença de genes codificando resistência a um antibiótico acontecia de forma aleatória, foi submetida a uma pressão externa (aplicações do antibiótico na colônia) e passou por um processo de seleção natural: o genótipo resistente ao antibiótico, melhor adaptado para sobreviver e gerar descendentes, foi selecionado sobre os demais.

\subsubsection{Mini-glossário}

Resumo das palavras-chave apresentadas na seção anterior:

- Um gene é uma unidade genética responsável pela codificação de proteínas, e consequentemente por construir e manter a estrutura das células de um indivíduo.

- O genótipo é o conjunto de genes de um indivíduo. Em conjunto com fatores ambientais, gera todas as características observáveis de um indivíduo. 
- Uma população pode ser entendida como um conjunto de indivíduos que, num determinado momento e local, procriam e compartilham dos mesmos genes.

- O fitness é uma medida da aptidão de um determinado genótipo em se reproduzir e sobreviver.

Pode ser interpretado como o número médio relativo de filhos produzidos por um determinado genótipo da população [8]. Ou seja, genótipos com maior fitness são capazes de manifestar características que os tornam mais propensos a se reproduzir que os demais.

Outra interpretação para o fitness seria com relação a sua capacidade de sobrevivência: a razão entre a frequência de um determinado genótipo nos adultos da população pela frequência deste genótipo nos indivíduos da geração seguinte, no momento do nascimento [22].

- Mutação é qualquer alteração que aconteça no material genético. Pode aparecer, por exemplo, na divisão celular ou durante a reprodução assexuada.

- O processo de deriva gênica é aquele onde mudanças nas frequências gênicas na população ocorrem por conta do acaso. Mais evidente em populações pequenas, está sempre presente em qualquer população.

- O processo de seleção natural é aquele através do qual indivíduos melhor adaptados ao ambiente prevalecem em detrimento daqueles menos aptos a sobreviver.

Os genótipos com menor fitness são removidos da população com o passar das gerações, favorecendo a sobrevivência dos genótipos melhor adaptados ao ambiente.

- Evolução é o processo gradual através do qual os organismos vivos se desenvolvem e mudam com o tempo. Pode ser causada por diversos fatores como por exemplo: mutações, migração, deriva gênica e seleção natural. 


\section{Capítulo 3}

\section{O modelo GMS}

Nos trabalhos [12] [13] [14] Guiol, Machado e Schinazi apresentam um modelo estocástico para o processo de evolução. Para facilitar a escrita, nesse texto chamaremos este modelo de "GMS" por conta das iniciais dos autores. A proposta é elaborar um modelo simples que descreva qualitativamente a evolução de uma espécie através do processo de seleção natural.

Inicialmente surgiu como uma alternativa ao trabalho de Bak-Sneppen [2]. Neste artigo, $N$ indivíduos são dispostos num círculo, e a cada um deles associa-se um número, chamado fitness, sorteado uniformemente em $[0,1]$. A cada passo de tempo elimina-se o indivíduo com menor fitness, e sorteia-se um novo fitness para substituir o anterior. Além disso, os dois vizinhos do fitness alterado também são sorteados novamente. Através de simulações, Bak e Sneppen sugerem que a distribuição dos fitnesses converge para uma Uniforme em $\left(f_{\star}, 1\right]$ para algum $f_{\star}$ com valor próximo a $2 / 3$.

No modelo GMS a população não é fixa e as interações entre indivíduos não são abordadas explicitamente. Mesmo assim é possível demonstrar analiticamente que o modelo apresenta um comportamento similar ao que foi sugerido pelas simulações de Bak-Sneppen [2]. Para uma descrição mais detalhada e comparação entre os trabalhos, veja a seção 5.1 .

O modelo GMS parece ser mais adequado ao caso de reprodução assexuada, ou seja, quando não há troca de informação genética entre dois indivíduos da população para gerar um terceiro. Exemplos de grupos que apresentam reprodução assexuada são: bactérias, estrelas e pepinos do mar, entre outros.

\subsection{Modelo a tempo contínuo}

Considere um ambiente onde convivem um número aleatório de genótipos de uma mesma espécie. Começamos com um único genótipo no ambiente. Novos genótipos surgem no sistema a uma taxa $\lambda$, e genótipos existentes são extintos a uma taxa $\mu$.

Cada genótipo estará associado a seu respectivo fitness. Usaremos aqui uma interpretação um pouco mais abrangente do que a formal adotada na genética de populações. Para nós, o fitness será uma representação numérica da capacidade de um determinado genótipo em se perpetuar ao longo do tempo na população.

Portanto, o fitness de cada genótipo será representado por um número sorteado segundo uma distribuição Uniforme em $[0,1]$ no momento de seu nascimento. Estes sorteios são independentes entre si e independentes de tudo o mais no sistema. 
A vantagem dos fitnesses mais altos fica evidente quando acontece um evento de morte: o genótipo eliminado será sempre aquele com menor fitness.

Estamos interessados em saber como se comporta a distribuição dos fitnesses ao longo do tempo. Apresentaremos aqui uma versão um pouco simplificada de um resultado de Guiol et al. [13] [14] para os tempos de sobrevivência dos fitnesses na população em função das taxas $\lambda$ e $\mu$.

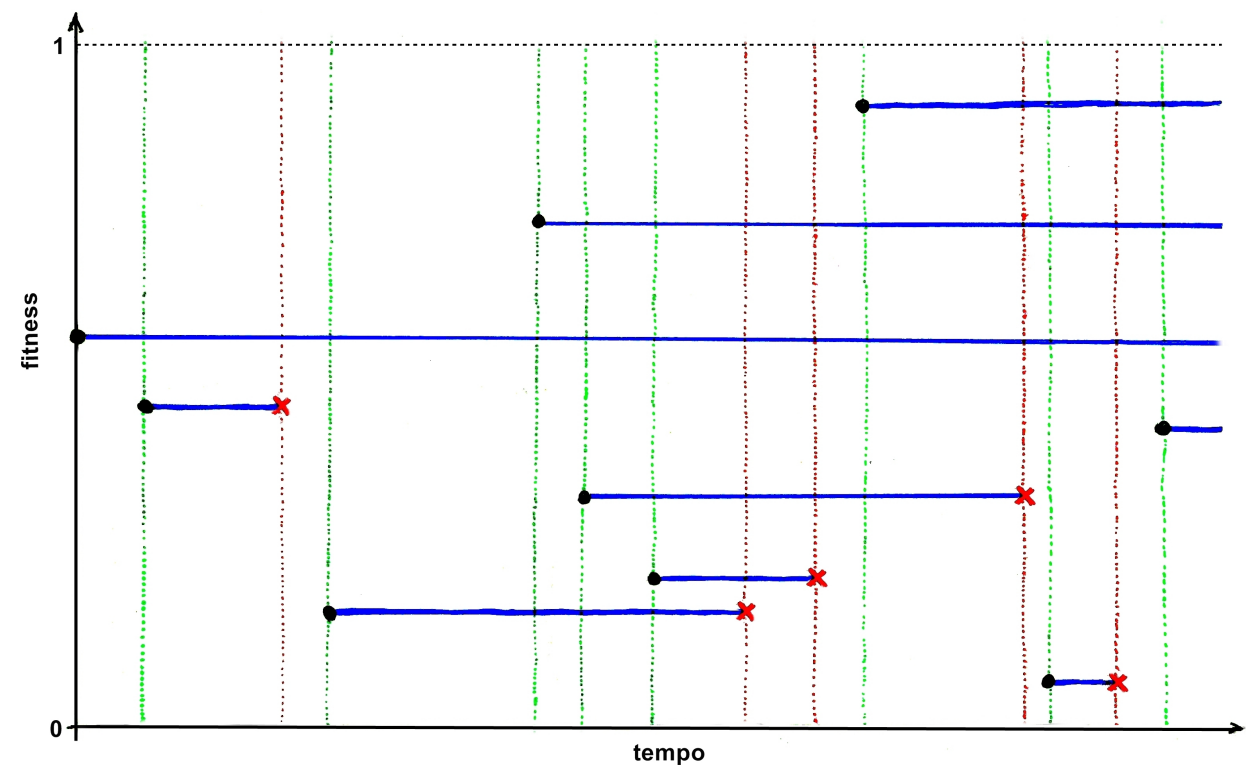

Figura 3.1: Exemplo de uma realização do modelo. - representa um nascimento, $\mathrm{x}$ representa uma morte e as linhas contínuas representam o tempo de vida dos fitnesses.

Teorema 3.1. (Guiol et al. [12])

Seja $f \in[0,1]$ o fitness inicial do sistema. Seja $\tau_{f}$ seu tempo de sobrevivência. Então:

(a) se $\lambda f<\mu$, com probabilidade 1 o fitness $f$ será eliminado do sistema em tempo finito.

(b) se $\lambda f>\mu$, temos para todo $t \geq 0$

$$
\mathbb{P}\left(\tau_{f}>t\right) \geq \mathbb{P}\left(\tau_{f}=\infty\right)=1-\frac{\mu}{\lambda f}
$$

ou seja, existe uma probabilidade positiva do fitness $f$ estar sempre presente no sistema.

(c) se $\lambda f=\mu$, temos para todo $t \geq 0$

$$
\lim _{t \rightarrow \infty} \sqrt{\frac{\pi}{2}(\lambda f+\mu) t} \mathbb{P}\left(\tau_{f}>t\right)=1
$$


Observemos que existe uma transição de fase no sistema quando $\lambda>\mu$ :

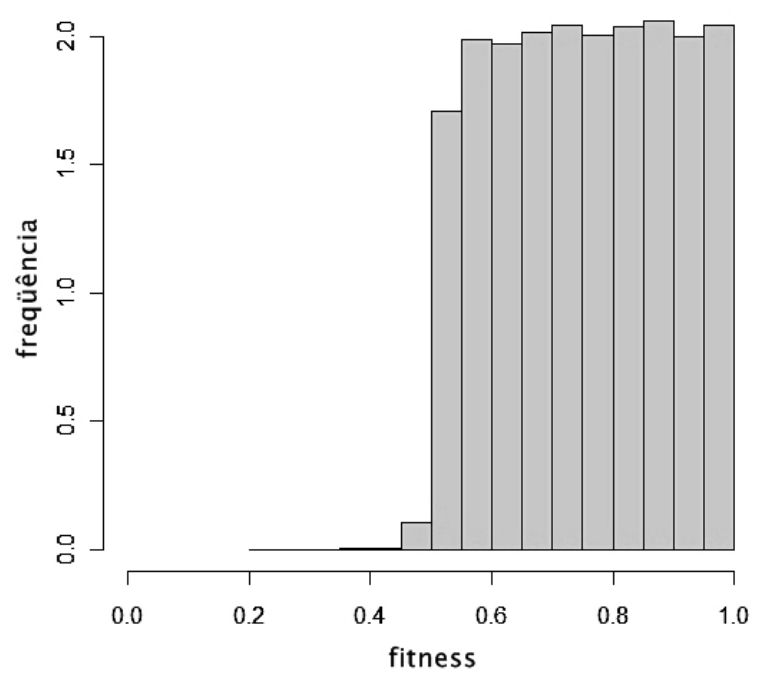

Figura 3.2: Genótipos com fitness menor que $f_{\star}=\mu / \lambda$ serão extintos da população, enquanto fitnesses maiores que $f_{\star}$ possuem probabilidade positiva de estarem sempre presentes no sistema. Além disso, acima de $f_{\star}$ os fitnesses se distribuem de maneira uniforme. Nesta figura, $f_{\star}=1 / 2$.

Demonstração. (Guiol et al. [12])

(a)

Seja $Y=\left\{y_{1}, y_{2}, \ldots\right\}$ o conjunto dos instantes de tempo em que acontece um evento de nascimento ou de morte. Seja $L=L(t)$ o número de nascimentos com fitness menor que $f$ até o tempo $t$. Notemos que o valor de $L$ só pode se alterar quando $t \in Y$.

Para $i \in \mathbb{N}, i \neq 0$, podemos escrever:

$$
\left\{\begin{array}{l}
\mathbb{P}\left(L\left(y_{j+1}\right)=i+1 \mid L\left(y_{j}\right)=i\right)=\frac{\lambda}{\lambda+\mu} f \\
\mathbb{P}\left(L\left(y_{j+1}\right)=i \mid L\left(y_{j}\right)=i\right)=\frac{\lambda}{\lambda+\mu}(1-f) \\
\mathbb{P}\left(L\left(y_{j+1}\right)=i-1 \mid L\left(y_{j}\right)=i\right)=\frac{\mu}{\lambda+\mu}
\end{array}\right.
$$

com

$$
\left\{\begin{array}{l}
\mathbb{P}\left(L\left(y_{j+1}\right)=1 \mid L\left(y_{j}\right)=0\right)=p_{0}=\frac{\lambda}{\lambda+\mu} f \\
\mathbb{P}\left(L\left(y_{j+1}\right)=0 \mid L\left(y_{j}\right)=0\right)=q_{0}=\frac{\lambda}{\lambda+\mu}(1-f)+\frac{\mu}{\lambda+\mu}
\end{array}\right.
$$

Para simplificar a notação, seja $p_{i}$ a probabilidade de uma transição do tipo $i \rightarrow i+1$ e $q_{i}$ a probabilidade de uma transição do tipo $i+1 \rightarrow i($ com $i \in \mathbb{N})$. 
Vale notar que aqui não sabemos se $f$ ainda está presente no sistema até o tempo $t$. O processo $L$ nos traz informação apenas sobre a quantidade de genótipos com fitness abaixo de $f$.

Porém, mostraremos que o processo $L$ assume o valor zero infinitas vezes, e portanto poderemos afirmar que quase certamente o fitness $f$ será eliminado do sistema.

Por hipótese, $\mu>\lambda f$ e daí

$$
\sum_{i=1}^{\infty} \frac{q_{i} q_{i-1} \cdots q_{1}}{p_{i} p_{i-1} \cdots p_{1}}=\sum_{i=1}^{\infty} \frac{\left(\frac{\mu}{\lambda+\mu}\right)^{i}}{\left(\frac{\lambda}{\lambda+\mu} f\right)^{i}}=\sum_{i=1}^{\infty}\left(\frac{\mu}{\lambda f}\right)^{i}=\infty
$$

Além disso,

$$
\sum_{i=1}^{\infty} \frac{p_{i-1} p_{i-2} \cdots p_{0}}{q_{i} q_{i-1} \cdots q_{1}}=\sum_{i=1}^{\infty} \frac{\left(\frac{\lambda}{\lambda+\mu} f\right)^{i}}{\left(\frac{\mu}{\lambda+\mu}\right)^{i}}=\sum_{i=1}^{\infty}\left(\frac{\lambda f}{\mu}\right)^{i}<\infty
$$

Usando a proposição 2.2, (3.1) e (3.2) implicam que $L$ é recorrente positivo. Portanto, $L$ assume o valor zero infinitas vezes com probabilidade 1 , e podemos concluir que o fitness $f$ será eliminado da população em tempo finito com probabilidade 1 .

(b)

Vamos considerar um subconjunto $\tilde{Y}$ do $Y$ definido no item anterior, composto dos instantes de tempo em que acontece ou um nascimento com fitness $\leq f$ ou um evento de morte.

Para cada $n \in \mathbb{N}$ defina $S_{n}$ o número de espécies com fitness $\leq f$ no tempo $\tilde{y}_{n}$.

Observe que $\left\{S_{n}, n \in \mathbb{N}\right\}$ é um passeio aleatório com transições:

$$
\begin{array}{ll}
i \rightarrow i+1 \quad \text { com probabilidade } & p=\frac{\lambda f}{\lambda f+\mu} \\
i \rightarrow i-1 \quad \text { com probabilidade } & q=1-p
\end{array}
$$

Como $\left\{\tau_{f}>t\right.$ para algum $\left.t\right\} \supset\left\{\tau_{f}>t \quad \forall t\right\}=\left\{\tau_{f}=\infty\right\}$, consideremos o evento $\left\{\tau_{f}=\infty\right\}$.

Este é equivalente a $S_{n}$ nunca ser igual a zero, dado que começou em 1.

Ou seja, podemos pensar como se fosse um problema do tipo "ruína do jogador", onde a "fortuna" $S_{n}$ é ilimitada superiormente e o jogador só sai do jogo quando perde todo seu dinheiro. No nosso caso, calcular $\mathbb{P}\left(\tau_{f}=\infty\right)$ é o mesmo que calcular a probabilidade de nunca sair do jogo.

Mas (vide (2.5) da seção 2.1.2) sabemos que

$$
\mathbb{P}\left(S_{n}>0 \quad \forall \mathrm{n} \mid S_{0}=1\right)=1-\frac{q}{p}
$$


Portanto,

$$
\begin{aligned}
\mathbb{P}\left(\tau_{f}>t\right) & \geq \mathbb{P}\left(S_{n}>0 \quad \forall \mathrm{n} \mid S_{0}=1\right) \\
& =\frac{2 p-1}{p} \\
& =\left(\frac{2 \lambda f}{\lambda f+\mu}-1\right) \frac{\lambda f+\mu}{\lambda f} \\
& =\frac{\lambda f-\mu}{\lambda f} \\
& =1-\frac{\mu}{\lambda f}
\end{aligned}
$$

(c)

Neste caso, como $\lambda f=\mu$ temos $\mathbb{P}\left(S_{n+1}=i+i \mid S_{n}=i\right)=\mathbb{P}\left(S_{n+1}=i-i \mid S_{n}=i\right)=\frac{1}{2}$, ou seja, $S_{n}$ é um passeio aleatório simples simétrico.

\section{Defina:}

$B(t)=$ número de nascimentos com fitness menor que $f$ até o tempo $t$,

$D(t)=$ número de eventos de morte até o tempo $t$,

$N(t)=B(t)+D(t)$.

Observe que $B(t)$ e $D(t)$ são processos de Poisson com taxas $\lambda f$ e $\mu$, respectivamente. Como estes processos são independentes, temos que $N(t)$ será um processo de Poisson com média $\lambda f+\mu$. Além disso, $N(t)$ representa o número de saltos do passeio $S_{n}$ até o tempo $t$.

Agora,

$$
\begin{aligned}
\left\{\tau_{f}>t\right\} & =\bigcup_{n=0}^{\infty}\{N(t)=n\} \cap\left\{\tau_{f}>t\right\} \\
\Downarrow & \\
\mathbb{P}\left(\tau_{f}>t\right) & =\sum_{n=0}^{\infty} \mathbb{P}\left(N(t)=n, \tau_{f}>t\right) \\
& =\sum_{n=0}^{\infty} \mathbb{P}\left(\tau_{f}>t \mid N(t)=n\right) \mathbb{P}(N(t)=n) \\
& =\sum_{n=0}^{\infty} \nu_{n} \mathbb{P}(N(t)=n)
\end{aligned}
$$

onde $\nu_{n}=\mathbb{P}\left(\tau_{f}>t \mid N(t)=n\right)$ é a probabilidade do passeio aleatório $S_{n}$ não ser igual 0 nenhuma vez em $n$ passos, dado que $S_{0}=1$.

Vamos encontrar limitantes inferior e superior para $\mathbb{P}\left(\tau_{f}>t\right)$, e mostrar que ambos convergem para o mesmo valor. 
Primeiramente, o limitante inferior.

Fixe $\varepsilon>0$. Defina o conjunto $E_{t}=\left\{n=\frac{N(t)}{t}\right.$, com $\left.t \in \mathbb{R} \mid \lambda f+\mu-\varepsilon<\frac{N(t)}{t}<\lambda f+\mu+\varepsilon\right\}$.

Temos que

$$
\mathbb{P}\left(\tau_{f}>t\right)=\sum_{n=0}^{\infty} \nu_{n} \mathbb{P}(N(t)=n) \geq \sum_{n \in E_{t}} \nu_{n} \mathbb{P}(N(t)=n)
$$

Seja $u_{2 k}=\mathbb{P}\left(S_{2 k}=0 \mid S_{0}=0\right)=\left(\begin{array}{c}2 k \\ k\end{array}\right) \frac{1}{2^{2 k}}$, conforme (2.2) na seção 2.1.1.

Se definirmos $T_{0}$ como o primeiro instante em que o passeio $S_{n}$ atinge o zero após o primeiro passo, temos:

$$
\begin{aligned}
u_{2 k} & =\mathbb{P}\left(S_{2 k}=0 \mid S_{0}=0\right) \\
& =\mathbb{P}\left(T_{0}>2 k \mid S_{0}=0\right) \\
& =\frac{1}{2} \mathbb{P}\left(T_{0}>2 k-1 \mid S_{0}=1\right)+\frac{1}{2} \mathbb{P}\left(T_{0}>2 k-1 \mid S_{0}=-1\right) \\
& =\mathbb{P}\left(T_{0}>2 k-1 \mid S_{0}=1\right)
\end{aligned}
$$

Mas $\nu_{n}=\mathbb{P}\left(T_{0}>n \mid S_{0}=1\right)$. De (3.3) vemos que $\nu_{n}=u_{n+1}$ quando $n$ é ímpar. Além disso, um caminho com $S_{0}=1$ só poderá assumir o valor zero em passos de tempo ímpares, portanto $\nu_{2 n}=\nu_{2 n-1}=u_{2 n}$. Ou seja,

$$
\nu_{n}= \begin{cases}\left(\begin{array}{c}
2 n \\
n
\end{array}\right) \frac{1}{2^{2 n}} & \text { se } n \text { é par } \\
\left(\begin{array}{c}
2 n+2 \\
n+1
\end{array}\right) \frac{1}{2^{2 n+2}} & \text { se } n \text { é ímpar }\end{cases}
$$

Usando a aproximação de Stirling (veja (2.4))

$$
u_{2 n} \approx \frac{1}{\sqrt{n \pi}}
$$

De modo que

$$
\sqrt{(n / 2) \pi} \nu_{n} \approx 1
$$

Assim, existe $K \in \mathbb{N}$ tal que, para $n \geq K$, podemos escrever $\left|\sqrt{n \pi / 2} \nu_{n}-1\right|<\varepsilon$.

Mas isso implica

$$
\frac{1-\varepsilon}{\sqrt{n \pi / 2}} \leq \nu_{n} \leq \frac{1+\varepsilon}{\sqrt{n \pi / 2}}
$$




\section{Considere agora}

$$
t \geq \frac{K}{(\lambda f+\mu-\varepsilon)}
$$

Temos

$$
\begin{aligned}
\mathbb{P}\left(\tau_{f}>t\right) & \geq \sum_{n \in E_{t}} \nu_{n} \mathbb{P}(N(t)=n) \\
& \geq(1-\varepsilon) \sum_{(3.4)}(n \pi / 2)^{-1 / 2} \mathbb{P}(N(t)=n) \\
& \geq(1-\varepsilon)(\pi(\lambda f+\mu-\varepsilon) t / 2)^{-1 / 2} \sum_{n \in E_{t}} \mathbb{P}(N(t)=n) \\
& =(\pi .5) \\
& (\lambda f+\mu-\varepsilon) t / 2)^{-1 / 2}(1-\varepsilon) \mathbb{P}\left(E_{t}\right)
\end{aligned}
$$

Mas $N(t)$ é um processo de Poisson com média $\lambda f+\mu$, daí $\lim _{t \rightarrow \infty} \frac{N(t)}{t}=\lambda f+\mu$ e $\lim _{t \rightarrow \infty} \mathbb{P}\left(E_{t}\right)=1$.

Reescrevendo a desigualdade acima,

$$
\sqrt{\frac{\pi}{2}(\lambda f+\mu-\varepsilon) t / 2} \mathbb{P}\left(\tau_{f}>t\right) \geq(1-\varepsilon) \mathbb{P}\left(E_{t}\right)
$$

Tomando o limite quando $t \rightarrow \infty$ e fazendo $\varepsilon \rightarrow 0$,

$$
\lim _{t \rightarrow \infty} \sqrt{\frac{\pi}{2}(\lambda f+\mu-\varepsilon) t} \mathbb{P}\left(\tau_{f}>t\right) \geq 1
$$

Vamos agora encontrar um limitante superior para $\mathbb{P}\left(\tau_{f}>t\right)$.

Seja $E_{t}$ como definido acima.

$$
\begin{aligned}
\mathbb{P}\left(\tau_{f}>t\right) & =\sum_{n=0}^{\infty} \nu_{n} \mathbb{P}(N(t)=n) \\
& =\sum_{n \in E_{t}} \nu_{n} \mathbb{P}(N(t)=n)+\sum_{n \in E_{t}{ }^{c}} \nu_{n} \mathbb{P}(N(t)=n) \\
& \leq \sum_{n \in E_{t}} \nu_{n} \mathbb{P}(N(t)=n)+\sum_{n \in E_{t}^{c}} \mathbb{P}(N(t)=n) \\
& =\sum_{n \in E_{t}} \nu_{n} \mathbb{P}(N(t)=n)+\mathbb{P}\left(E_{t}^{c}\right) \\
& \leq \underset{(3.4)}{\leq}(\pi(\lambda f+\mu-\varepsilon) t / 2)^{-1 / 2}(1+\varepsilon) \mathbb{P}\left(E_{t}\right)+\mathbb{P}\left(E_{t}^{c}\right)
\end{aligned}
$$

E portanto

$$
\sqrt{\frac{\pi}{2}(\lambda f+\mu-\varepsilon) t} \mathbb{P}\left(\tau_{f}>t\right) \leq(1+\varepsilon) \mathbb{P}\left(E_{t}\right)+\sqrt{\frac{\pi}{2}(\lambda f+\mu-\varepsilon) t} \mathbb{P}\left(E_{t}{ }^{\mathrm{c}}\right)
$$


Como $\lim _{t \rightarrow \infty} \mathbb{P}\left(E_{t}\right)=1$ e $\lim _{t \rightarrow \infty} \mathbb{P}\left(E_{t}^{c}\right)=0$, fazendo $\varepsilon \rightarrow 0$ vemos finalmente que

$$
\lim _{t \rightarrow \infty} \sqrt{\frac{\pi}{2}(\lambda f+\mu-\varepsilon) t} \mathbb{P}\left(\tau_{f}>t\right) \leq 1
$$

o que conclui a demonstração.

Em Guiol et al. [14] os autores demonstram um resultado mais geral para esse modelo. O tempo de sobrevivência de um fitness $f$ segue uma distribuição de Bessel e não é afetado por fitnesses superiores a ele que estejam presentes na população.

\subsection{Modelo a tempo discreto}

Em Guiol et al. [13] os autores apresentam uma versão do modelo a tempo discreto.

As idéias são as mesmas, a única diferença é que a cada passo de tempo um evento de nascimento acontece com probabilidade $p$, e um evento de morte com probabilidade $q=1-p$. Fazendo um paralelo com o modelo a tempo contínuo, teríamos $p=\frac{\lambda}{\lambda+\mu}$ e $q=\frac{\mu}{\lambda+\mu}$.

Neste artigo, os autores também demonstram uma versão mais forte do resultado apresentado na seção anterior. Vamos enunciá-la aqui:

Seja $p \in(1 / 2,1)$ e $f_{\star}=\frac{q}{p} \in[0,1]$. Sejam $L_{n} \subset\left[0, f_{\star}\right)$ e $R_{n} \subset\left(f_{\star}, 1\right]$ os conjuntos dos fitnesses menores e maiores que $f_{\star}$ no instante $n$, respectivamente.

Teorema 3.2. (Guiol et al. [13])

Sejam $1 / 2<p \leq 1$ e $f_{\star}=\frac{q}{p}$.

(a) O número $\left|L_{n}\right|$ de genótipos com fitnesses menores que $f_{\star}$ é uma cadeia de nascimento-morte recorrente nula. Em particular, o conjunto $L_{n}$ é quase certamente vazio infinitas vezes.

(b) Sejam $f_{\star}<a<b<1$, então

$$
\left.\lim _{n \rightarrow \infty} \frac{1}{n} \mid R_{n} \cap\right] a, b[\mid=p \mathbb{P}(a<X<b) \text { q.c. }
$$

onde $X$ é uma variável aleatória com mesma distribuição daquela do sorteio dos fitnesses.

Esse resultado é mais geral do que o da seção anterior porque vale para sorteios de fitnesses realizados a partir de qualquer distribuição contínua. Sua demonstração pode ser encontrada em [13].

Observe que o fitness crítico aqui é o mesmo do teorema 3.1, e que também temos uma transição de fase em $f_{\star}$. De fato, se $\frac{\lambda}{\lambda+\mu}=p \in(1 / 2,1)$, teremos

$$
\frac{\mu}{\lambda}=\frac{q}{p}=f_{\star}<1 \Rightarrow \mu<\lambda
$$

e portanto estamos na mesma situação com transição de fase do teorema 3.1. 


\section{Capítulo 4}

\section{Variações do modelo}

\subsection{Caso subcrítico}

O que acontece com os tempos de vida dos fitnesses quando a taxa de morte é maior que a taxa de nascimento? Até agora só sabemos pelo teorema 3.1 que nesta situação todos os fitnesses desaparecerão do sistema com probabilidade 1 .

Uma possível abordagem para esse problema é pensar num sistema alternativo similar ao original. Fixado $N \in \mathbb{N}$, a cada nascimento o novo fitness será sorteado de acordo com uma distribuição uniforme em $\{1 / N, 2 / N, \ldots,(N-1) / N, 1\}$.

É como se empobrecessemos a classificação dos fitnesses: aqui contamos apenas o número de genótipos com fitness nos conjuntos $[0,1 / N],(1 / N, 2 / N], \ldots,((N-1) / N, 1]$.

Podemos pensar que estamos num sistema de filas com prioridades onde existem clientes dos tipos $1,2, \ldots, N$. Clientes tipo $j$ sempre têm prioridade sobre os clientes dos tipos $j+1, \ldots, N$.

"Ser atendido" aqui representa uma "morte" no sistema original. Para termos algo equivalente ao modelo GMS, devemos olhar apenas para o que acontece na fila, sem considerar o cliente em atendimento. No sistema original, este indivíduo já está morto. Dessa forma, clientes com baixa prioridade na fila representam indivíduos com maior fitness na população.

Para aproximar o modelo GMS com essa formulação alternativa vamos considerar o limite quando $N \rightarrow \infty$.

Entretanto, a dinâmica para os dois modelos não é exatamente a mesma. Nas regras aproximadas, cada categoria possui sua própria fila, ou seja, todos os fitnesses entre $((j-1) / N, j / N]$ se organizam numa subfila dentro desse intervalo. Mas esta subfila está ordenada por ordem de chegada, portanto estamos permitindo eventualmente que fitnesses mais altos sejam eliminados do sistema antes de outros mais baixos pertencentes à mesma categoria.

\section{Teorema 4.1.}

Para a formulação aproximada do modelo GMS, quando $\lambda<\mu$ e $F$ é um sorteio uniforme em $[0,1]$, o tempo médio de vida de um fitness $f \in[0,1]$ é

$$
\mathbb{E}\left(\tau_{f}\right)=\frac{\lambda}{(\mu-f \lambda)^{2}}
$$




\section{Demonstração.}

Da seção 2.1.3 temos que, numa fila com $N$ prioridades, o tempo médio de espera de um cliente do tipo $j$ será:

$$
\mathbb{E}\left(\tau_{j}\right)=\frac{\lambda}{\mu^{2}\left(1-\frac{1}{\mu} \sum_{i=1}^{j-1} \lambda_{i}\right)\left(1-\frac{1}{\mu} \sum_{i=1}^{j} \lambda_{i}\right)}
$$

onde $\mu$ aqui é a taxa de morte, e $\lambda=\sum_{j=1}^{N} \lambda_{j}$ é a taxa de nascimento de novos fitnesses.

Como nosso objetivo é aproximar o modelo com sorteio uniforme dos fitnesses, fazemos $\lambda_{j}=\lambda / N$ para todo $j$. Portanto,

$$
\mathbb{E}\left(\tau_{j}\right)=\frac{\lambda}{\mu^{2}\left(1-\frac{(j-1) \lambda}{N \mu}\right)\left(1-\frac{j \lambda}{N \mu}\right)}
$$

Queremos saber o tempo médio de vida de um fitness $f \in[0,1]$. Mas $f$ estará na categoria $j=\lceil f N\rceil$. Assim, aproximamos seu tempo médio de vida por:

$$
\begin{aligned}
\mathbb{E}\left(\tau_{f}\right) & =\lim _{N \rightarrow \infty} \frac{\lambda}{\mu^{2}\left(1-\frac{\lambda}{\mu}\left(\frac{\lceil f N-1\rceil}{N}\right)\right)\left(1-\frac{\lambda}{\mu} \frac{\lceil f N\rceil}{N}\right)} \\
& =\frac{\lambda}{\mu^{2}\left(1-\frac{f \lambda}{\mu}\right)^{2}} \\
& =\frac{\lambda}{(\mu-f \lambda)^{2}}
\end{aligned}
$$

Observe que, como estamos no caso subcrítico $(\mu>\lambda)$, teremos sempre $f \in[0,1]$ sem qualquer problema para o denominador da fração acima.

Podemos observar nas figuras ao lado que de fato existe diferença entre as duas abordagens para a modelagem. O sistema aproximado não consegue descrever exatamente o comportamento do modelo GMS. As simulações sugerem que este modelo aproximado poderia talvez servir como limitante inferior para os tempos médios de vida dos fitnesses. 
$\mu / \lambda=1.1$

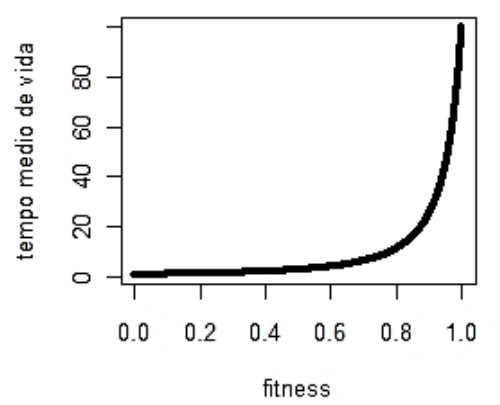

$\mu / \lambda=2$

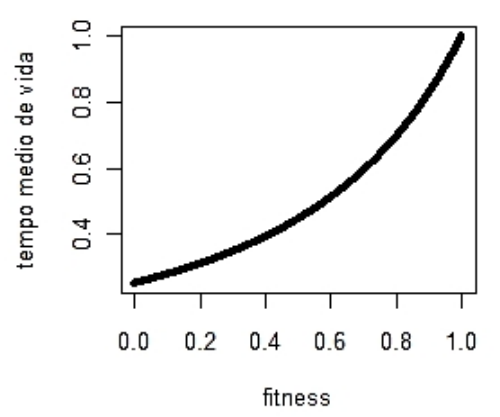

$\mu / \lambda=1.5$

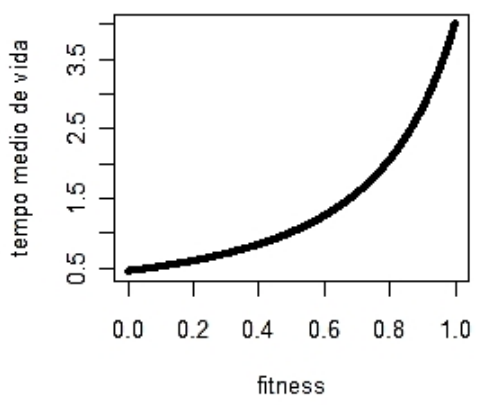

$\mu / \lambda=2.5$

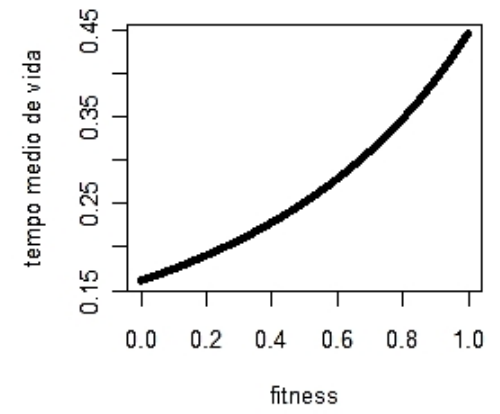

Figura 4.1: Gráficos dos tempos médios de vida no sistema para diferentes fitnesses segundo os resultados teóricos para o sistema aproximado.

$\mu / \lambda=1.1$

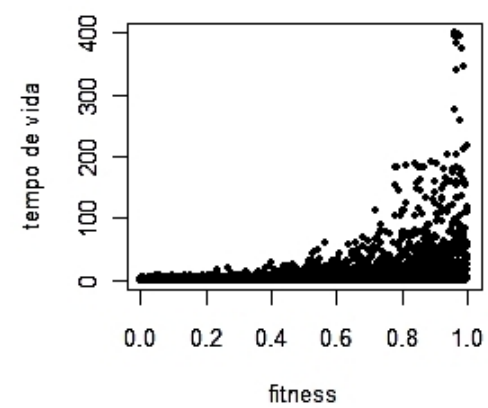

$\mu / \lambda=2$

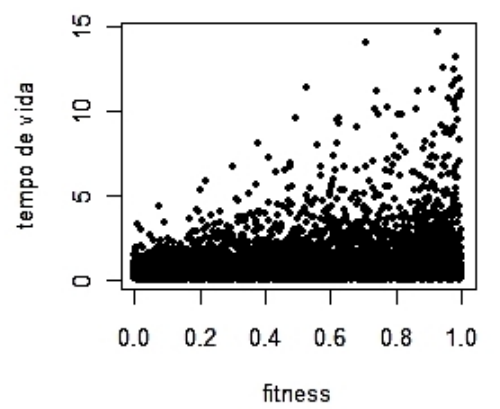

$\mu / \lambda=1.5$

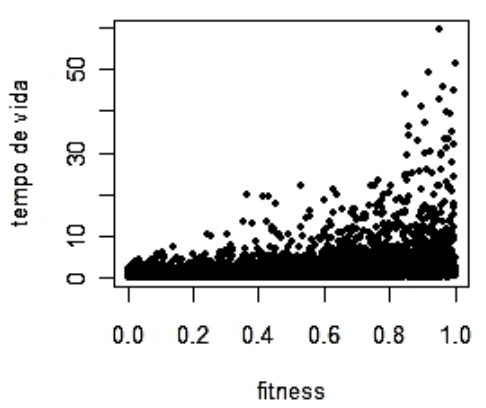

$\mu / \lambda=2.5$

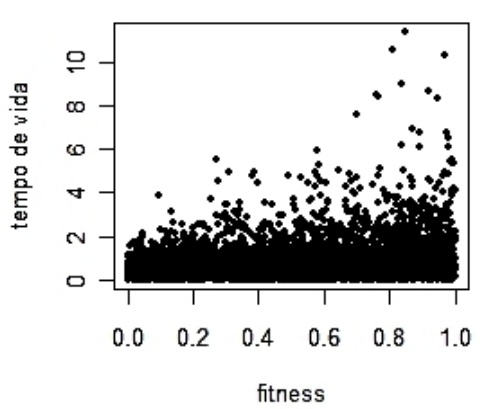

Figura 4.2: Simulações para os tempos de vida de diferentes fitnesses no modelo GMS original. 


\subsection{Ambiente com capacidade finita}

Na seção 2.2 vimos que a seleção natural ocorre quando a população está sujeita a algum tipo de pressão ambiental (seja uma limitação espacial, nos recursos alimentares etc.). Porém, no modelo do capítulo 3 permitimos um número aleatório de fitnesses no sistema. Consequentemente, estamos admitindo que a população pode crescer indefinidamente.

Nesse caso, o esperado seria que a população evoluísse principalmente de forma aleatória (com mais influência da deriva gênica). Isso se deve ao fato de que diferenças nos fitnesses não representariam nenhuma particular vantagem ou desvantagem à sobrevivência de um indivíduo. Ou seja, precisamos de alguma maneira incorporar uma "restrição" no modelo para aproximá-lo da dinâmica observada na natureza.

Portanto, vamos considerar agora que podem conviver ao mesmo tempo no ambiente no máximo um número $N$ fixo de genótipos. Essa seria uma primeira aproximação para algum tipo de restrição espacial ao crescimento da população.

\section{Teorema 4.2.}

Em um ambiente com capacidade finita no número de genótipos, nenhum fitness sobreviverá para sempre quase certamente.

\section{Demonstração.}

Seja $f \in[0,1]$, e suponhamos que em determinado instante $f$ é o maior dos fitnesses presentes no sistema. Para facilitar a escrita vamos considerar $t=0$ nesse instante, e definir $S_{t}$ como a posição de $f$ na população no tempo $t$. Ou seja, $S_{t}=j$ significa que no tempo $t$ o fitness $f$ é o $j$-ésimo da população. Vale notar que $S_{0}=N$ e que se $S_{t}=0$ então $f$ não está mais presente no tempo $t$.

Observemos que a escala de tempo para $S_{t}$ não é a mesma que a do modelo GMS. Para esse processo, estaremos olhando apenas para os instantes de tempo em que o número de genótipos na população se altera, isto é, para os instantes em que acontece um nascimento ou uma morte.

Seja $X$ uma variável aleatória com mesma distribuição que a do sorteio dos fitness. Para $n \in \mathbb{N}$,

$$
\begin{gathered}
\begin{cases}\mathbb{P}\left(S_{n}=j+1 \mid S_{n-1}=j\right)=\mathbb{P}(X<f) \frac{\lambda}{\lambda+\mu}, & j \in\{0, \ldots, N-1\} \\
\mathbb{P}\left(S_{n}=j \mid S_{n-1}=j\right)=(1-\mathbb{P}(X>f)) \frac{\lambda}{\lambda+\mu}, & j \in\{1, \ldots, N-1\} \\
\mathbb{P}\left(S_{n}=j-1 \mid S_{n-1}=j\right)=\frac{\mu}{\lambda+\mu} & j \in\{0, \ldots, N-1\}\end{cases} \\
\left\{\begin{array}{l}
\mathbb{P}\left(S_{n}=N \mid S_{n-1}=N\right)=\frac{\lambda}{\lambda+\mu} \\
\mathbb{P}\left(S_{n}=N-1 \mid S_{n-1}=N\right)=\frac{\mu}{\lambda+\mu} \\
\mathbb{P}\left(S_{n}=0 \mid S_{n-1}=0\right)=\frac{\mu}{\lambda+\mu}
\end{array}\right.
\end{gathered}
$$


Podemos comparar esse processo com um passeio aleatório $Z_{n}$ com barreiras em 0 e $N$, com as seguintes probabilidades de transição:

$$
\begin{gathered}
\left\{\begin{array}{l}
\mathbb{P}\left(Z_{n}=j+1 \mid Z_{n-1}=j\right)=\frac{\lambda}{\lambda+\mu}, \quad j \in\{0,1, \cdots N-1\} \\
\mathbb{P}\left(Z_{n}=j-1 \mid Z_{n-1}=N\right)=\frac{\mu}{\lambda+\mu}, \quad j \in\{1,2, \cdots N\}
\end{array}\right. \\
\left\{\begin{array}{l}
\mathbb{P}\left(Z_{n}=N \mid Z_{n-1}=N\right)=\frac{\lambda}{\lambda+\mu} \\
\mathbb{P}\left(Z_{n}=0 \mid Z_{n-1}=0\right)=\frac{\mu}{\lambda+\mu}
\end{array}\right.
\end{gathered}
$$

Vale ressaltar que $\mathbb{P}\left(S_{n}=0\right) \geq \mathbb{P}\left(Z_{n}=0\right)$, pois a probabilidade de $Z_{n}$ "saltar para cima" é maior que a de $S_{n}$, enquanto a probabilidade de "saltar para baixo" é a mesma nos dois processos.

Mas $Z_{n}$ é um passeio aleatório simples com barreiras. Seja $\tilde{Z}_{n}$ o processo análogo a $Z_{n}$, mas sem a barreira em $N$. Usando o lema 2.1 e a aproximação (2.4) temos:

$$
\begin{aligned}
\mathbb{P}\left(Z_{1} \neq 0, Z_{2} \neq 0, \ldots, Z_{2 n} \neq 0\right) & \leq \mathbb{P}\left(\tilde{Z}_{1} \neq 0, \tilde{Z}_{2} \neq 0, \ldots, \tilde{Z}_{2 n} \neq 0\right) \\
& =\mathbb{P}\left(\tilde{Z}_{2 n}=0\right) \\
& =\left(\begin{array}{c}
2 n \\
n
\end{array}\right) \frac{1}{2^{2 n}}
\end{aligned}
$$

E assim

$$
\begin{aligned}
\mathbb{P}\left(S_{n} \neq 0 \forall n \in \mathbb{N}\right) & \leq \mathbb{P}\left(Z_{n} \neq 0 \forall n \in \mathbb{N}\right) \\
& =\lim _{n \rightarrow \infty} \mathbb{P}\left(Z_{1} \neq 0, Z_{2} \neq 0, \ldots, Z_{2 n} \neq 0\right) \\
& \leq \lim _{n \rightarrow \infty}\left(\begin{array}{c}
2 n \\
n
\end{array}\right) \frac{1}{2^{2 n}} \\
& =0
\end{aligned}
$$

Com isso, podemos dizer que quase certamente nenhum fitness sobreviverá para sempre na população.

De um ponto de vista biológico, isso significa que não importa quão bem adaptado ou "desenvolvido" esteja um genótipo hoje, eventualmente surgirão outros melhor adaptados às condições ambientais que o substituirão gradualmente, e por fim ele desaparecerá da população. 


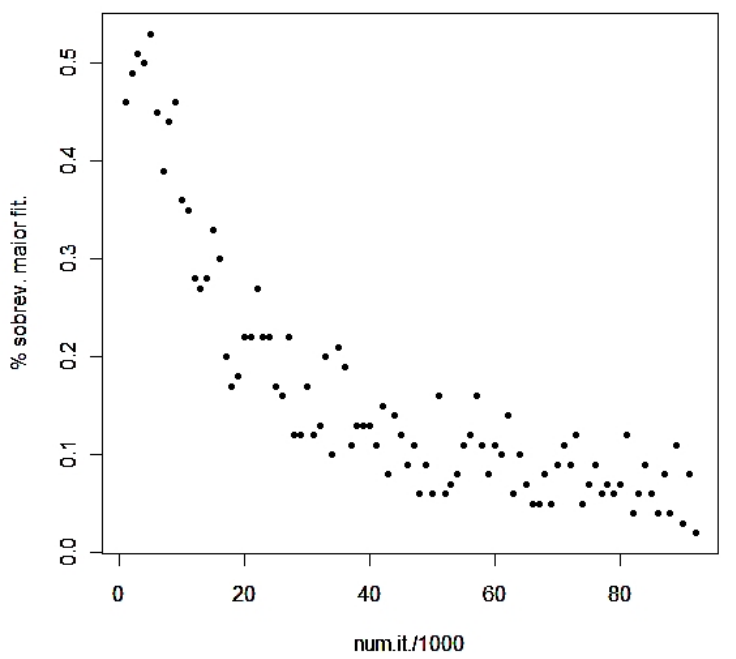

Figura 4.3: Simulação para o modelo com capacidade finita. Parâmetros: $\lambda=2 / 3$ e $\mu=1 / 3$. No eixo horizontal temos o número de eventos de nascimento e morte observados dividido por $10^{3}$. Para cada $t$ no eixo horizontal repetimos 100 vezes a simulação do modelo no caso de capacidade finita com $t$ observações. Em cada repetição guardamos o maior fitness presente no instante em que a população atinge sua capacidade máxima e observamos se ele está ou não presente após as $t$ observações. Calculamos o percentual de sobrevivência desses indivíduos durante as repetições. Estes percentuais estão no eixo vertical do gráfico acima. 


\section{Capítulo 5}

\section{Comentários, críticas, conclusões}

\subsection{Comparação}

Apresentamos aqui uma descrição dos modelos de Bak-Sneppen e GMS, da forma como estão apresentados em seus artigos originais.

\subsubsection{Modelo Bak-Sneppen}

Em 1993, Bak e Sneppen propuseram um modelo para a evolução de espécies.

O modelo é definido da seguinte maneira no artigo [2]:

1) $N$ espécies são dispostas num grafo circular - cada espécie tem exatamente dois vizinhos.

2) Cada espécie recebe um fitness, que será sorteado aleatoriamente e uniformemente em $[0,1]$.

A cada passo de tempo, o sistema é atualizado da seguinte maneira:

3) Localiza-se a espécie com menor fitness. Esta será substituída por outra com um novo fitness, sorteado da mesma maneira que os anteriores.

4) Os dois vizinhos da espécie alterada no item anterior também terão seus fitnesses novamente sorteados.

A disposição das espécies no grafo tem como objetivo representar algum tipo de interação entre estas (predação, competição, comensalismo, cooperação etc.). O número de espécies permanece sempre fixo e igual a $N$.

A justificativa para se alterar também os vizinhos no processo de atualização seria de que as espécies que antes interagiam com a que foi substituída sofreriam também alterações com a mudança. Esse é um ponto interessante do modelo: considerar as interações entre os vértices do grafo e sua influência no processo evolutivo.

Em seu artigo, os autores mostram através de simulações que existiria um valor crítico $f_{\star} \in[0,1]$. Sugerem que o menor fitness da população nunca teria valor superior a $f_{\star}$; enquanto acima deste valor crí́tici os fitnesses se distribuiriam uniformemente Ou seja, após um longo período de tempo haveria poucos fitnesses abaixo deste valor crítico. Além disso, torna-se mais provável que os vizinhos de vértices que sofrerem mutações sejam os próximos a trocarem seus fitnesses seguindo a regra do sistema. 


\subsubsection{Modelo GMS}

Uma das motivações para este modelo foi o artigo de Bak-Sneppen [2], que os autores consideraram um tanto artificial de um ponto de vista biológico.

A versão a tempo contínuo do modelo GMS como descrito nos artigos [12] [13] [14] é a seguinte:

1) Considere um ambiente onde podem conviver um número aleatório de espécies.

2) Novas espécies surgem a uma taxa $\lambda$ e espécies existentes são extintas a uma taxa $\mu$.

3) Num evento de nascimento, a nova espécie é associada a um número sorteado aleatoriamente e uniformemente em $[0,1]$, que representará o fitness da espécie.

Estes sorteios são independentes entre si, e independentes de tudo o mais no sistema.

4) Num evento de morte, a espécie eliminada será aquela com menor fitness.

Este modelo não considera explicitamente possíveis interações entre espécies. O número de espécies no sistema é aleatório, e será determinado de acordo com os parâmetros de nascimento e morte.

Em seus artigos, os autores demonstram analiticamente que existe um fitness crítico (dependente das taxas $\lambda$ e $\mu$ ) acima do qual os fitnesses se distribuem uniformemente, e abaixo do qual todo fitness desaparecerá após um tempo finito. Este resultado é bem parecido ao que sugerem as simulações do artigo de BakSneppen.

\subsection{Discussão}

O modelo de Bak-Sneppen e o modelo GMS apresentam resultados matemáticos interessantes, e inclusive já serviram como motivação para outros trabalhos (como exemplo, os artigos de Gillet et al. [9], Grinfeld et al. [11], Sole e Bascompte [29], Ben-Ari et al. [3], Michael e Volkov [19]).

Porém, conforme descritos nos artigos originais, estes modelos apresentam erros conceituais no que diz respeito aos aspectos biológicos que se propõem a descrever.

Um ponto bastante explorado no modelo de Bak-Sneppen (e também presente no modelo GMS) se refere ao equilíbrio pontuado. As teorias de evolução por equilíbrio pontuado conjectura que a especiação (ou seja, o surgimento de novas espécies por conta da evolução) aconteceria em "saltos", contrastando períodos longos sem alterações com mudanças rápidas e bruscas gerando especiação. Essa interpretação se deve principalmente por conta da análise de registros fósseis, que podem apresentar padrões desse tipo.

Mas essa é uma interpretação equivocada. A evolução e especiação são processos graduais, e mesmo esses registros fósseis não contradizem esse fato - inclusive existem espécies que apresentam registros fósseis de uma evolução gradual.

A especiação ocorre principalmente por conta de algum tipo de isolamento de um grupo de indivíduos da população original. Este grupo isolado, por ser menor, está mais facilmente sujeito a apresentar variações genéticas do que a população original. Portanto, a deriva gênica e seleção natural atuarão nele com mais intensidade. Dessa forma, é mais difícil que existam registros fósseis dos estágios intermediários nessa pequena população, e por isso parece que a especiação aconteceu de forma brusca. 
Para uma ilustração de como registros fósseis podem sugerir a idéia de equilíbrio pontuado, veja a página [1]. Para uma discussão mais aprofundada, vide por exemplo os textos de Mayr [18] [17].

O gradualismo foi uma das idéias de Darwin que mais demorou a ser incorporada na biologia. Mas atualmente é bem aceito entre biólogos e evolucionistas que o processo de especiação ocorre de forma gradual. Por exemplo, Dobzhansky [6] afirma que as hipóteses de mutações bruscas estão ultrapassadas e praticamente já não possuem mais adeptos. Um outro exemplo é o texto de Mayr [18], onde podemos encontrar diversas justificativas de que o processo evolutivo ocorre continuamente.
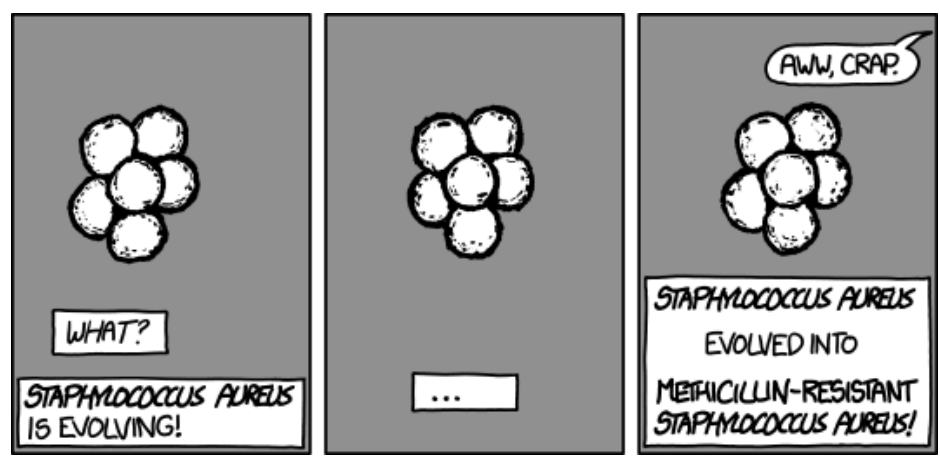

Figura 5.1: Uma charge sobre o processo de evolução (http://xkcd.com/1147/)

Outro ponto relevante refere-se a unidade de seleção - informalmente, "o que" está sofrendo seleção natural. Em geral entende-se que a seleção natural acontece ao nível dos indivíduos (Fisher [8], Mayr [18]).

Existiu alguma polêmica quanto a possibilidade da chamada seleção de grupos (vide, por exemplo, Dawkins [5] e Smith [28]). Esta hipótese surgiu para explicar a razão de se observarem na natureza comportamentos aparentemente prejudiciais para o indivíduo, porém benéficos para o grupo no qual ele se encontra. Resultados decorrentes da chamada teoria dos jogos evolucionária são bastante aceitos para explicar porque a seleção de grupos na verdade é uma seleção de indivíduos tradicional.

De forma resumida, o surgimento e prevalência de comportamentos aparentemente em prol de um bem comum são explicados através de escolhas individuais. Cada membro da população toma suas decisões sozinho. A adoção de uma postura altruísta torna-se mais vantajosa dependendo da estrutura da população. Assim, parece que uma determinada característica (ou estratégia) do grupo está sendo "selecionada", mas na verdade cada indivíduo tem suas próprias escolhas de comportamento.

Algumas referências para este assunto são Nowak [20] Pacheco e Santos [25], Pinheiro et al. [21]. As páginas [15] e [16] disponibilizam algum conteúdo teórico sobre o assunto e também programas para simular diversas dinâmicas e tipos de sistemas.

Contudo, é bastante aceito que não existe seleção no nível das espécies (Mayr [18], Smith [28]). Portanto é mais razoável considerarmos o genótipo como unidade de seleção ao invés de espécies inteiras, como é feito nos artigos originais de Bak-Sneppen [2] e Guiol et. al [13] [14].

De modo geral, recomendo a leitura dos apêndices de Mayr [18]. O autor apresenta de forma clara e concisa várias perguntas e respostas sobre a evolução. Além disso, faz um resumo das principais críticas feitas à teoria evolucionária e explica porque cada uma delas está incorreta ou imprecisa.

Outra leitura para um primeiro contato com as teorias genética e evolucionária é o livro de Schultz [27]. Os temas são apresentados de forma didática e divertida, bem interessante para curiosos ou leigos no assunto. 
A pergunta natural agora é: como podemos adaptar os modelos originais de modo a torná-los mais coerentes com as teorias evolucionárias? Uma primeira alternativa seria reinterpretá-los tomando a unidade de seleção como sendo o genótipo. Isso foi feito com o modelo GMS ao longo dessa dissertação.

Já com relação ao modelo de Bak-Sneppen precisaríamos de um pouco mais de cuidado, pois não é muito evidente o que se estaria representando através da regra de alterar também o fitness dos vizinhos adjacentes no grafo. Além disso, essa mudança repentina nos fitnesses vizinhos ainda seria um tanto contrastante com o observado na natureza.

\subsection{Sugestões para trabalhos futuros}

Algumas outras idéias de modificações para o modelo GMS seriam:

1. Inclusão da deriva gênica.

Na seção 2.2 vimos que em qualquer população sempre atuam diversas "forças" que geram evolução, em maior ou menor intensidade. Até agora consideramos principalmente a seleção natural ao adotarmos a regra de eliminar sempre os menores fitnesses.

Outro processo bem importante é o da chamada deriva gênica, onde flutuações nas frequências dos genótipos da população se alteram por conta de efeitos estocásticos. É por conta da deriva que um indivíduo com características altamente favoráveis pode ser eliminado da população.

Para incluir a deriva na dinâmica do modelo, uma possibilidade seria alterar a regra de morte: ao invés de uma escolha determinística do fitness a ser eliminado, podemos permitir que eventualmente um fitness qualquer da população seja morto. Isto é, com uma determinada probabilidade $\gamma$ eliminaríamos o menor fitness presente; e com probabilidade $1-\gamma$ escolheríamos ao acaso quem seria eliminado.

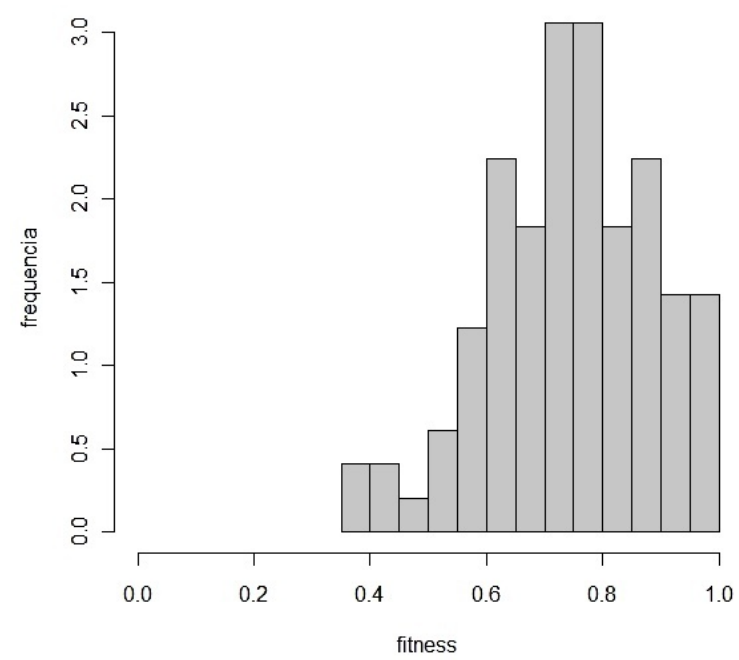

Figura 5.2: Simulação do modelo GMS com capacidade finita para o número de genótipos e deriva gênica. Parâmetros: $\lambda=2 / 3, \mu=1 / 3, \gamma=1 / 2$, número máximo de genótipos $=100$. 
2. Alteração do mecanismo de reprodução.

Da maneira como está descrito, o modelo parece mais apropriado para descrever populações que se reproduzem de forma assexuada.

Como mencionado anteriormente, as mutações e alterações nos fitnesses acontecem de forma lenta e gradual. Uma possibilidade para aproximar esse fato seria a alteração da regra de nascimento: ao invés de sortearmos aleatoriamente os novos fitnesses, sorteraríamos primeiro uma "mãe" dentro da população, e o novo fitness seria escolhido de acordo com uma distribuição dependente do fitness da mãe. Este sorteio poderia ser uniforme, mas parece mais razoável priorizar fitnesses mais altos (uma vez que estes tem maior propensão a se perpetuar).
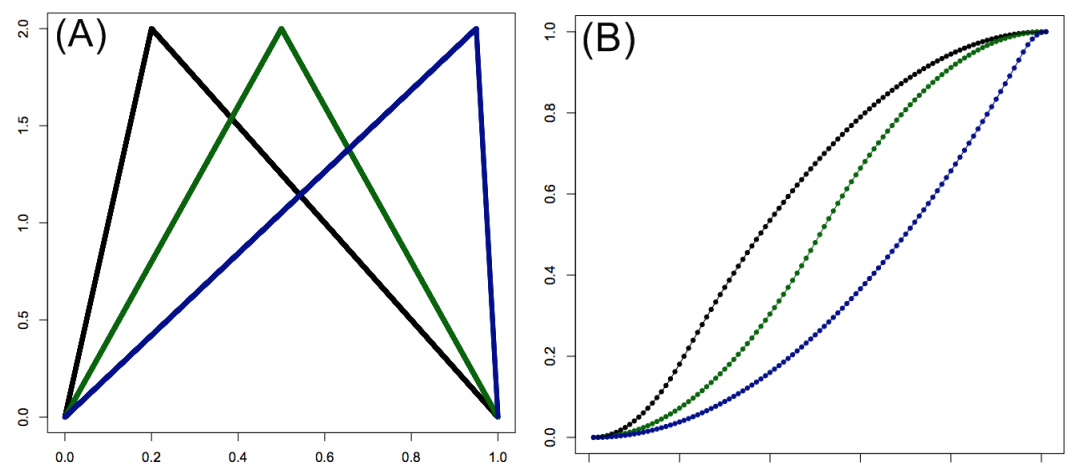

Figura 5.3: Sugestão de uma possível distribuição para o sorteio dos fitnesses levando em conta a influência de alguma "mãe" dentro da população. Na figura, mostramos os gráficos para (A) a função densidade e (B) a função de distribuição do sorteio de novos fitnesses com "mães" $=0.2,0.5$ e 0.95 .

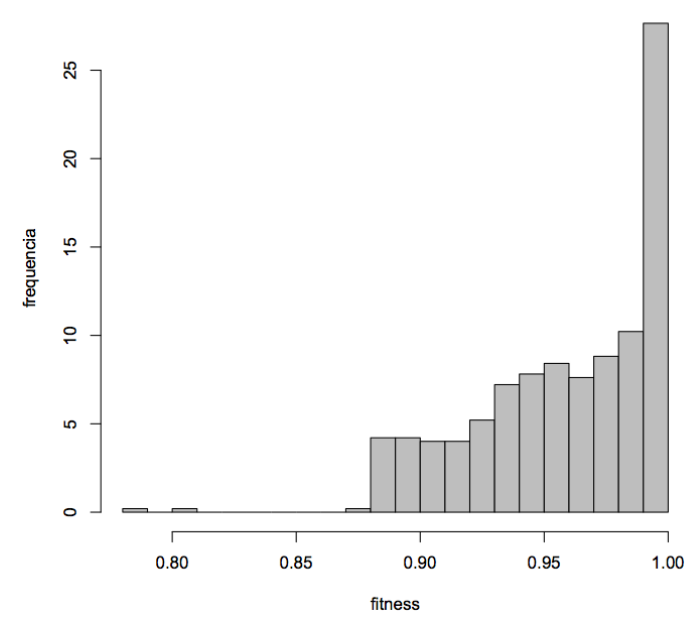

Figura 5.4: Simulação do modelo com capacidade finita para o número de genótipos e sorteio dos fitnesses conforme a distribuição da figura acima.

Outra possibilidade seria alterar as regras de nascimento para considerar o caso de reprodução sexuada. Seria necessário encontrar uma maneira razoável de sortear os novos fitnesses a partir de alguma relação estabelecida com outros dois genótipos presentes no sistema ("pai" e "mãe" do novo fitness). 


\section{Referências Bibliográficas}

[1] Entendendo a evolução. http://www.ib.usp.br/evosite/evo101/VIIA1bPunctuated.shtml.

[2] P. Bak and K. Sneppen. Punctuated equilibrium and criticality in a simple model of evolution. Physical Review Letters, 71:4083-4086, Dez 1993.

[3] I. Ben-Ari, A. Matzavinos, and A. Roitershtein. On a species survival model. Electronic Communications in Probability, 16:226-233, 2010.

[4] C. Darwin. On the origin of species. John Murray, 1859.

[5] R. Dawkins. The selfish gene. Oxford University Press, 1976.

[6] T. Dobzhansky. Genética do processo evolutivo. Poligono, 1973.

[7] W. Feller. An introduction to probability theory and its applications. John Wiley, 1968. vol.1, 3a ed., cap. 3.

[8] R. Fisher. The genetic theory of natural selection. Oxford University Press, 1930.

[9] A. Gillett, R. Meester, and P. V. D. Wal. Maximal avalanche in the bak-sneppen model. Journal of Applied Probability, 43(3):840-851, Set 2006.

[10] S. Gould. The structure of evolutionary theory. Harvard University Press, 2002.

[11] M. Grinfeld, P. Knight, and A. Wade. Bak-sneppen-type models and rank-driven processes. Physical Review E, 84:041124, Out 2011.

[12] H. Guiol, F. Machado, and R. Schinazi. Stochastic model for species survival. Comunicação privada, 2010.

[13] H. Guiol, F. Machado, and R. Schinazi. A stochastic model of evolution. Markov Processes and Related Fields, 17(2):253-258, 2010.

[14] H. Guiol, F. Machado, and R. Schinazi. On a link between a species survival time in an evolution model and the bessel distributions. A ser publicado no Brazilian Journal of Probability and Statistics, 2012. preprint: http://www.imstat.org/bjps/papers/BJPS167.pdf.

[15] C. Hauert. Virtuallabs. http://www.univie.ac.at/virtuallabs/, 2008.

[16] C. Hauert. Evoludo. http://wiki.evoludo.org/index.php?title=EvoLudo, 2012.

[17] E. Mayr. Speciational evolution or punctuated equilibria (do livro: The Dynamics of Evolution). Cornell University Press, 1992. pags. 21-48.

[18] E. Mayr. What evolution is. Basic Books, 2001. 
[19] S. Michael and S. Volkov. On the generalization of the gms evolutionary model. Markov Processes and Related Fields, 18(2):311-322, 2011.

[20] M. Nowak. Evolutionary dynamics. Harvard University Press, 2006.

[21] F. Pinheiro, F. Santos, and J. Pacheco. How selection pressure changes the nature of social dilemmas in structured populations. New Journal of Physics, 14 (073035), Jul 2012.

[22] M. Ridley. Evolution. Blackwell Publishing, 2004. 3a ed.

[23] S. Ross. Stochastic processes. John Wiley, 1995. 2a ed., cap. 4.

[24] S. Ross. Introduction to probability models. John Wiley, 2000. 7a ed., cap. 8.

[25] F. Santos and J. Pacheco. Scale-free networks provide a unifying framework for the emergence of cooperation. Physical Review Letters, 95:098104, Ago 2005.

[26] R. Schinazi. Classical and spatial stochastic processes. Birkháuser, 1999. 2a ed., cap. I e II.

[27] M. Schultz. Genética e DNA em quadrinhos. Blucher, 2011. Arte de Z. e K. Cannon.

[28] J. M. Smith. Evolutionary genetics. Oxford University Press, 1989.

[29] R. Sole and J. Bascompte. Are critical phenomena relevant to large-scale evolution? Proceedings of the Royal Society: Biological Sciences, 263(1367):161-168, Fev 2006.

[30] J. Virtamo. Lecture notes on queueing theory. http://www.netlab.tkk.fi/opetus/s383143/kalvot/english.shtml, 2005. 